\title{
Heat treatment of $\mathrm{Al}-\mathrm{Si}-\mathrm{Cu}-\mathrm{Mg}$ casting alloys
}

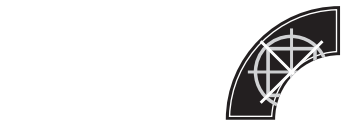

SCHOOL OF ENGINEERING

JÖNKÖPING UNIVERSITY

Department of Mechanical Engineering, Materials and Manufacturing - Casting SCHOOL OF ENGINEERING, JÖNKÖPING UNIVERSITY

JÖNKÖPING, SWEDEN

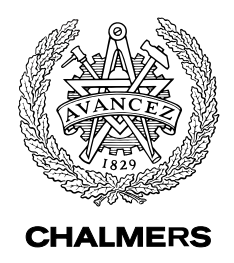

Department of Materials and Manufacturing Technology

CHALMERS UNIVERSITY OF TECHNOLOGY

Göteborg, Sweden 2011 


\section{Heat treatment of $\mathrm{Al}-\mathrm{Si}-\mathrm{Cu}-\mathrm{Mg}$ casting alloys}

Emma Sjölander

Department of Mechanical Engineering

School of Engineering, Jönköping University

SE-551 11 Jönköping, Sweden

emma.sjolander@jth.hj.se

Copyright (C) Emma Sjölander

ISBN 978-91-7385-529-7

Doktorsavhandlingar vid

Chalmers tekniska högskola

Ny serie $\mathrm{Nr} 3210$

ISSN 0346-718X

\section{Published and Distributed by}

Chalmers University of Technology

Department of Materials and Manufacturing Technology

Division of Product Development

SE - 41296 Göteborg, Sweden

\section{Printed in Sweden by}

Chalmers Reproservice

Göteborg, 2011 




\title{
ABSTRACT
}

\section{Heat treatment of $\mathrm{Al}-\mathrm{Si}-\mathrm{Cu}-\mathrm{Mg}$ casting alloys EMMA SJÖLANDER}

\author{
Department of Mechanical Engineering, Materials and Manufacturing - Casting \\ SCHOOL OF ENGINEERING, JÖNKÖPING UNIVERSITY \\ Department of Materials and Manufacturing Technology \\ CHALMERS UNIVERSITY OF TECHNOLOGY
}

Environmental savings can be made by increasing the use of aluminium alloys in the automotive industry as the vehicles can be made lighter. Increasing the knowledge about the heat treatment process is one task in the direction towards this goal. The aim of this work is to investigate and model the heat treatment process for Al-Si casting alloys. Three alloys containing $\mathrm{Mg}$ and/or $\mathrm{Cu}$ were cast using the gradient solidification technique to achieve three different coarsenesses of the microstructure and a low amount of defects.

Solution treatment was studied by measuring the concentration of $\mathrm{Mg}, \mathrm{Cu}$ and $\mathrm{Si}$ in the $\alpha-\mathrm{Al}$ matrix using wavelength dispersive spectroscopy (WDS) after various times at a solution treatment temperature. A diffusion based model was developed which estimates the time needed to obtain a high and homogenous concentration of alloying elements for different alloys, temperatures and coarsenesses of the microstructure. It was shown that the yield strength after artificial ageing is weakly dependent on the coarseness of the microstructure when the solution treatment time is adjusted to achieve complete dissolution and homogenisation.

The shape and position of ageing curves (yield strength versus ageing time) was investigated empirically in this work and by studying the literature in order to differentiate the mechanisms involved. A diffusion based model for prediction of the yield strength after different ageing times was developed for $\mathrm{Al}-\mathrm{Si}-\mathrm{Mg}$ alloys. The model was validated using data available in the literature. For $\mathrm{Al}-\mathrm{Si}-\mathrm{Cu}-\mathrm{Mg}$ alloys further studies regarding the mechanisms involved need to be performed.

Changes in the microstructure during a heat treatment process influence the plastic deformation behaviour. The Hollomon equation describes the plastic deformation of alloys containing shearable precipitates well, while the Ludwigson equation is needed when a supersaturated solid solution is present. When non-coherent precipitates are present, none of the equations describe the plastic deformation well. The evolution of the storage rate and recovery rate of dislocations was studied and coupled to the evolution of the microstructure using the Kocks-Mecking strain hardening theory.

Keywords: Cast aluminium alloys, Heat Treatment, Solution Treatment, Artificial Ageing, Tensile Properties, Plastic Deformation, Microstructure, Modelling 


\section{ACKNOWLEDGEMENTS}

I would like to express my sincere gratitude to:

The European Project NADIA (New Automotive components Designed for and manufactured by Intelligent processing of light Alloys) for financial support.

The partners involved in the NADIA project, especially MAGMAsoft and University of Padova, for good cooperation.

Dr. Salem Seifeddine for being an excellent supervisor, always taking the time to discuss with his students and for nice travel company.

Professor Ingvar L. Svensson for supervision and support and for giving me the opportunity to do this work.

Dr. Nils-Eric Andersson for scientific discussions.

Leif Andersson, Lasse Johansson, Toni Bogdanoff and Märta Thor for helping me with experimental equipment.

Master student Andreas Ljung and Bachelor student Krzysztof Kwapisz for help with experimental work.

Qumex Materialteknik AB for the optical emission spectrometer analyses.

All colleagues at the department of Mechanical Engineering at Jönköping University for creating a superb working environment.

Martin Selin and Mathias König for studying, running, cooking, eating and drinking company.

Kristina Lewin and Hans-Erik Ekström at Sapa Technology for awakening my interest for aluminium during my Master thesis at the company.

Family and Friends. 


\section{SUPPLEMENTS}

The following supplements constitute the basis of this thesis.

Supplement I - E. Sjölander, S. Seifeddine: The heat treatment of $\mathrm{Al}-\mathrm{Si}-\mathrm{Cu}-\mathrm{Mg}$ casting alloys. Journal of Materials Processing Technology 210 (2010) 1249-1259.

Sjölander was the main author.

Supplement II - E. Sjölander, S. Seifeddine: Optimisation of solution treatment of cast Al-Si-Cu alloys. Materials and Design 31 (2010) S44-S49.

Sjölander was the main author. Seifeddine was adviser regarding the work. Sjölander performed the experimental part and evaluated the results. Seifeddine presented the work at the International Conference on Materials for Advanced Technologies, 2009,

Singapore.

Supplement III - E. Sjölander, S. Seifeddine: Optimisation of solution treatment of cast Al-7Si-0.3Mg and Al-8Si-3Cu-0.5Mg alloys. Submitted to Metallurgical and Materials Transactions A.

Sjölander was the main author. Seifeddine was adviser regarding the work. Sjölander performed the experimental part and evaluated the results.

Supplement IV - E. Sjölander, S. Seifeddine: Artificial ageing of Al-Si-Cu-Mg casting alloys. Submitted to Materials Science and Engineering A.

Sjölander was the main author. The experiments were performed by a Bachelor student under supervision of Seifeddine and Sjölander. Sjölander evaluated the results.

Supplement V - E. Sjölander, S. Seifeddine: Influence of alloy composition, solidification rate and artificial ageing on the plastic deformation of Al-Si-Cu-Mg casting alloys. Submitted to Materials Science and Engineering A.

Sjölander was the main author. The experiments were performed by a Bachelor student under supervision of Seifeddine and Sjölander. Sjölander evaluated the results.

Supplement VI - E. Sjölander, S. Seifeddine, I. L. Svensson: Modelling the yield strength of heat treated Al-Si-Mg casting alloys. Submitted to International Journal of Cast Metals Research.

Sjölander was the main author. Seifeddine and Svensson were advisers regarding the work. 


\section{NOMENCLATURE AND ABBREVIATIONS}

\footnotetext{
$b \quad$ magnitude of the Burgers vector $[\mathrm{m}]$

$C_{M}^{M g}, C_{M}^{S i} \quad$ concentration of $\mathrm{Mg}$ and $\mathrm{Si}$ respectively in the $\alpha-\mathrm{Al}$ matrix [wt\%]

$d \quad$ distance between the precipitates [m]

$D \quad$ diffusivity $\left[\mathrm{m}^{2} / \mathrm{s}\right]$

$f_{p p t} \quad$ fraction of precipitates [-]

$G_{\alpha} \quad$ shear modulus of the $\alpha-\mathrm{Al}$ phase $[\mathrm{Pa}]$

$k_{1} \quad$ parameter for storage of dislocations $\left[\mathrm{m}^{-1}\right]$

$k_{2} \quad$ parameter for recovery of dislocations [-]

$K \quad$ parameter related to the recovery rate of dislocations in the $\mathrm{KM}$ strain hardening theory [-]

$K_{1} \quad$ material parameter for the Hollomon and Ludwigson equations [Pa]

$K_{2} \quad$ material parameter for the Ludwigson equation $[\ln (\mathrm{Pa})]$

$k_{\text {coh }} \quad$ parameter for the coherency strengthening law [-]

$k_{D} \quad$ parameter for storage of dislocations at non-coherent precipitates $\left[\mathrm{m}^{-2}\right]$

$L \quad$ measured distance between $\mathrm{Mg} / \mathrm{Cu}$ rich phases $[\mathrm{m}]$

$M \quad$ the Taylor factor [-]

$n_{1} \quad$ strain hardening exponent for the Hollomon and Ludwigson equations [-]

$n_{2} \quad$ material parameter for the Ludwigson equation $[\ln (\mathrm{Pa})]$

$q \quad$ strength exponent for the superposition law [-]

$r_{\text {part }} \quad$ radius of the particle $[\mathrm{m}]$

$r_{p p t} \quad$ radius of the precipitate [m]

$r$ radius of the spherical diffusion field [m]

$t_{d} \quad$ dimensionless diffusion time $[-]$

$\alpha \quad$ parameter in the dislocation strengthening law [-]

$\beta \quad$ parameter related to the dislocation storage rate in the $\mathrm{KM}$ strain hardening theory when non-coherent precipitates are present $\left[\mathrm{Pa}^{2}\right]$
} 
constrained misfit parameter [-]

$\varepsilon_{p} \quad$ true plastic strain [-]

$\varepsilon_{p}^{i} \quad$ initial true plastic strain [-]

$v_{\alpha} \quad$ Poisson's ratio of the $\alpha$-Al matrix [-]

$\theta \quad$ strain hardening rate $[\mathrm{Pa}]$

$\theta_{0} \quad$ parameter related to the dislocation storage rate in the KM strain hardening theory $[\mathrm{Pa}]$

$\rho \quad$ dislocation density $\left[\mathrm{m}^{-2}\right]$

$\sigma \quad$ true stress $[\mathrm{Pa}]$

$\sigma_{\text {dis }} \quad$ dislocation strength $[\mathrm{Pa}]$

$\sigma_{\text {dis }}^{i} \quad$ initial dislocation strength [Pa]

$\sigma_{i} \quad$ intrinsic strength $[\mathrm{Pa}]$

$\sigma_{p p t} \quad$ strength contribution from precipitates $[\mathrm{Pa}]$

$\sigma_{s s} \quad$ solid solution strengthening $[\mathrm{Pa}]$

$\sigma_{\text {tot }} \quad$ total strength $[\mathrm{Pa}]$

$\sigma_{Y S} \quad$ yield strength $[\mathrm{Pa}]$

EDS energy dispersive spectroscopy

GP Guinier-Preston

HPDC high pressure die casting

KM Kocks-Mecking

LSW Lifshitz-Slyozov-Wagner

NA natural aged

OA overaged

OES optical emission spectroscopy

PA peak aged

PM permanent mould

SDAS secondary dendrite arm spacing

SEM scanning electron microscope

TEM transmission electron microscope

UA underaged

WDS wavelength dispersive spectroscopy 


\section{TABLE OF CONTENTS}

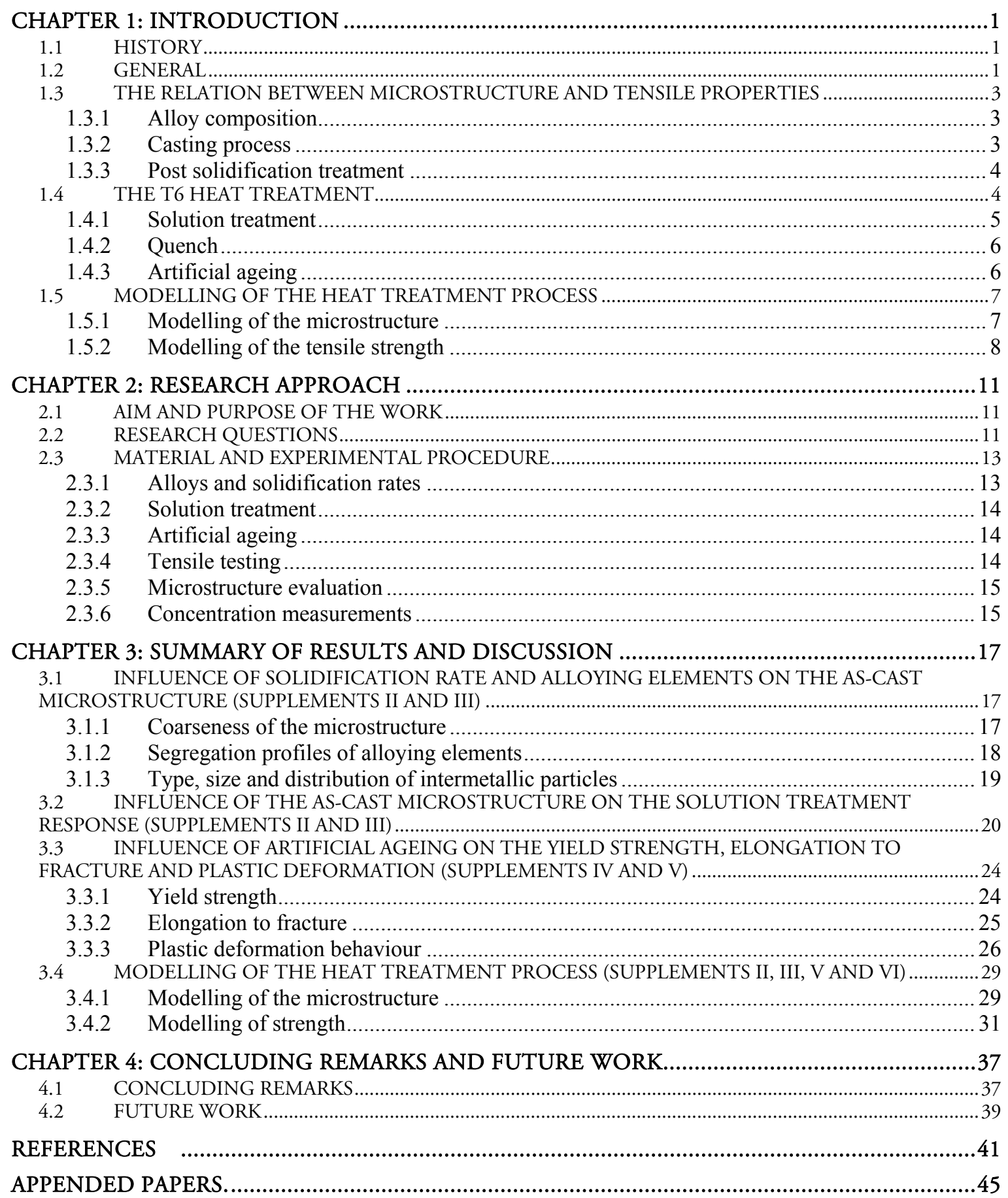




\section{INTRODUCTION}

\subsection{HISTORY}

Compared to other metals such as iron, copper, tin, etc aluminium is a relatively new material. Pure aluminium was first isolated around 1825. In 1845 a piece large enough to study its properties was extracted and it was concluded that aluminium is ductile and non magnetic [1]. The first factory for aluminium production was built in 1854 close to Paris. At this time aluminium was still produced by chemical means and was more expensive than gold [2]. In 1886 Hall and Héroult independently produced aluminium by electrolysis of alumina, $\mathrm{Al}_{2} \mathrm{O}_{3}$, dissolved in molten cryolite [1]. The production of high purity alumina from bauxite around 1890 was the last step in reaching a cost effective production of aluminium [1]. The electrolysis is however very energy intensive and the aluminium production plants (smelters) are placed in regions where electricity is cheap. Aluminium products have a long life and can be recycled using only $5 \%$ of the production energy.

In 1906 Dr. Alfred Wilm investigated the possibility to increase the strength of aluminium alloys $[3,4]$. He knew that the strength of steel could be increased by a high temperature treatment followed by a fast quench. Wilm applied the same procedure to aluminium alloys. Disappointed he observed a decrease rather than an increase in strength. However, at one occasion, Wilm quenched his samples and then left for the weekend. Returning, he was surprised to find that the strength of the samples had increased. Age hardening was discovered! The alloy Wilm used contained 3.5-5.5\% Cu and less than $1 \% \mathrm{Mg}$ and $\mathrm{Mn}$ and was subsequently named Duralumin. The discovery was followed by a search for other aluminium alloys which age harden.

The precipitates formed and which are responsible for hardening are too small to be seen in the optical microscope and researchers speculated about the reason for the increase in strength. Formation of precipitates from a supersaturated solid solution and their ability to block crystallographic slip was proposed as the reason for the increase in strength [3-5]. In 1937 the precipitates were detected experimentally for the first time by Guinier and Preston using x-ray diffraction and the precipitates were named Guinier-Preston, GP, zones [6]. It was not until the development of the transmission electron microscope, TEM, that the ideas of interactions between precipitates and dislocations could be confirmed.

\subsection{GENERAL}

Aluminium is a material of special interest due to its high strength to weight ratio. Further beneficial properties are that it is easy to recycle, it is corrosion resistant and has a high electrical and thermal conductivity. Less beneficial is its low strength at high temperature and low stiffness. Aluminium is used in five major areas; building and construction, containers and packaging, transportation, electrical conductors, machinery and equipment [2]. 
Aluminium alloys are designated as wrought and cast alloys. The Al-Si alloys are the largest group of cast alloys due to their excellent castability. Addition of Si increases the fluidity and decreases the solidification shrinkage, resulting in an increase in castability [7]. A further advantage is that Si can be added without increasing the density of the alloy. Si increases the strength and stiffness, but reduces the ductility. Commercial Al-Si casting alloys have Si concentrations in the range of 5 to $23 \mathrm{wt} \%$ [8]. Three different microstructures form depending on the $\mathrm{Si}$ concentration, i.e. the alloy can be hypoeutectic, eutectic or hypereutectic, see Figure 1a. The microstructure of the hypoeutectic alloys consists of $\alpha$-Al dendrites which solidify first followed by the Al-Si eutectic, see Figure 1c. The distance between the secondary dendrite arms, SDAS, in Figure $1 \mathrm{~b}$ is related to the local solidification time. Primary Si particles form first in hypereutectic alloys followed by the Al-Si eutectic, see Figure 1d. The Si concentration of alloys used in the automotive industry often ranges between 5 and $10 \mathrm{wt} \%$ and they are frequently used in applications such as engine blocks, cylinder heads and wheels. Hypereutectic alloys are used when increased wear properties are needed [1]. Typical applications are cylinder liners, pistons and piston rings.

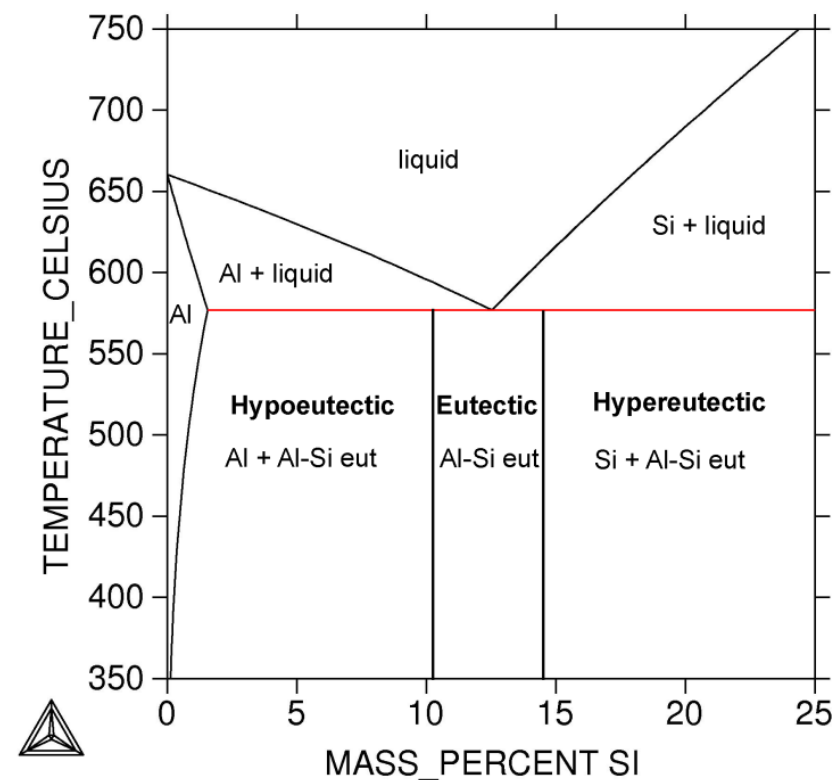

(a)

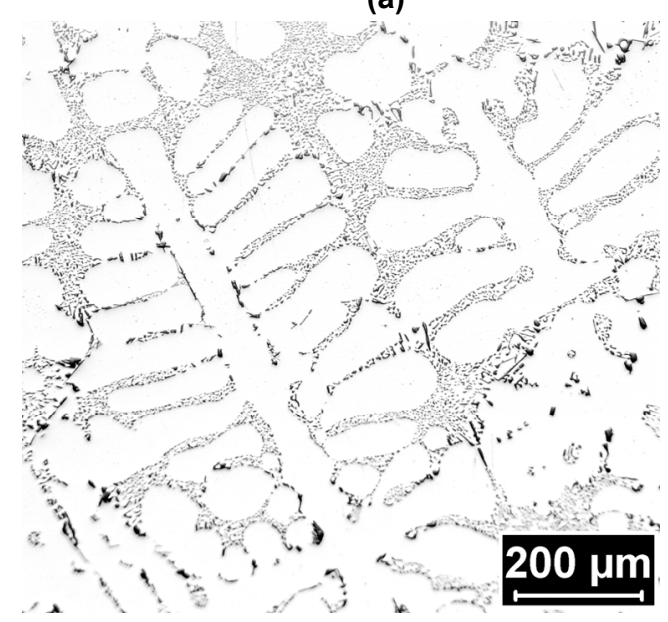

(c)

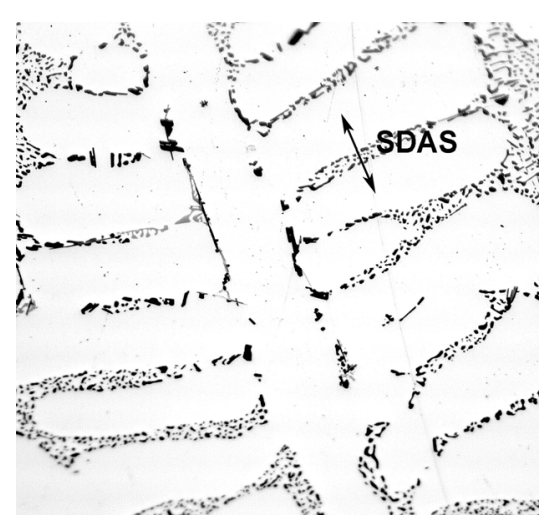

(b)

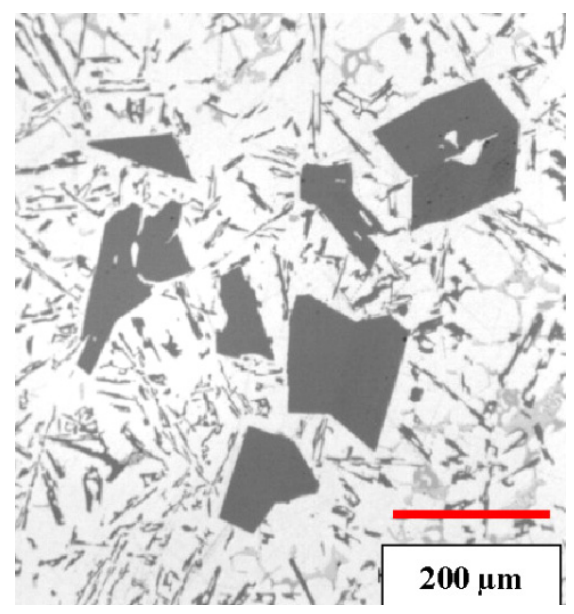

(d)

Figure 1 a) Al-Si phase diagram [9]. b) Illustration of SDAS. Microstructures of c) hypoeutectic and d) hypereutectic alloys [10]. 


\subsection{THE RELATION BETWEEN MICROSTRUCTURE AND TENSILE PROPERTIES}

The tensile properties of Al-Si casting alloys can be altered within a large spectrum by the choice of 1) alloy composition, 2) casting process and 3) post solidification treatment.

\subsubsection{Alloy composition}

The Si particles have a plate-like morphology in unmodified aluminium alloys, which act as crack initiators and have a negative influence on ductility [11]. The alloy ductility can be improved by changing the morphology of the Si particles towards a more fibrous form. This can be done by using a high cooling rate, by addition of a chemical modifier, by exposing the casting to a high temperature for long periods, or by a combination of these processes [12]. Strontium, Sr, is often used as a chemical modifier and small additions of 50-300 ppm are often made [13]. The Sr concentration needed to obtain a fibrous morphology depends on the purity of the melt; $\mathrm{Mg}$ for example negates some of the modifying effect $[13,14]$. The fibrous morphology obtained through $\mathrm{Sr}$ modification is much easier to fragment and spheroidize during solution treatment and the solution treatment time can be shortened [11].

$\mathrm{Cu}$, and $\mathrm{Mg}$ are added to increase the strength of the alloy, but this also lead to a reduction in ductility $[7,15]$. The strength and ductility obtained are affected by factors such as if the $\mathrm{Cu}$ and $\mathrm{Mg}$ are present as coarse phases after solidification, as atoms in solid solution, as GP zones formed at room temperature, or as precipitates formed during artificial ageing [7]. The coarse phases which may form during solidification are the $\mathrm{Al}_{2} \mathrm{Cu}$ phase and the $\mathrm{Q}$ $\mathrm{Al}_{5} \mathrm{Mg}_{8} \mathrm{Si}_{6} \mathrm{Cu}_{2}$ phase in Al-Si-Cu-Mg alloys $[16,17]$, while the $\pi-\mathrm{Al}_{8} \mathrm{Mg}_{3} \mathrm{FeSi}_{6}$ phase and the $\mathrm{Mg}_{2} \mathrm{Si}$ phase form in Al-Si-Mg alloys [18]. These coarse phases do not contribute to strength and their degree of influence on ductility depends on their distribution and size relative to the Si particles [19]. The strength increase obtained in the as-cast condition arises from atoms in solid solution and from GP zones which form at room temperature. The highest strength contribution is obtained when $\mathrm{Cu}$ and $\mathrm{Mg}$ are present as small precipitates after a heat treatment, but a reduction in ductility also results. Additions of $\mathrm{Cu}$ and $\mathrm{Mg}$ also leads to the formation of bands of coarse Si particles and an increased risk for shrinkage porosity due to an increased solidification interval, which may decrease the elongation to fracture [15].

Iron is often regarded as an undesirable impurity as it forms long and brittle $\beta-\mathrm{Al}_{5} \mathrm{FeSi}$ plates that initiate and link fracture. Fe is however needed to reduce die soldering in high pressure die casting, HPDC [7]. Manganese, Mn, is added to change the shape of the brittle $\beta$-Fe plates into the more compact $\alpha-\mathrm{Al}_{15}(\mathrm{Fe}, \mathrm{Mn})_{3} \mathrm{Si}_{2}$ phase having a Chinese script morphology, which has less tendency to initiate and link fracture [7]. The usefulness of Mn additions is however not clear. Mn additions have for example been shown to have a negative effect at low $\mathrm{Fe}$ concentrations, as the volume fraction of brittle intermetallic phases increases [20]. The size of the $\mathrm{Fe}$ rich phases can be refined by increasing the solidification rate, leading to an increase in elongation to fracture $[7,20]$. When $\mathrm{Cu}$ and $\mathrm{Mg}$ are present $\mathrm{Fe}$ containing phases in addition to the $\beta$-Fe may form as for example the $\pi$-Fe phase and the $\mathrm{Al}_{7} \mathrm{FeCu}_{2}$ phase [7].

Grain refinement is achieved by additions of Al-Ti-B master alloy. The grain size itself does not have a large influence on mechanical properties for casting alloys, but it does influence the distribution of phases and porosity [7].

\subsubsection{Casting process}

The casting process determines both the solidification rate and the defect content. Typical defects found in Al-Si casting alloys are oxides and pores. The defect content depends on the cleanliness of the melt and how it is introduced into the mould, while the solidification rate 
depends on the geometry of the component (wall thickness and mass centre) and the ability to remove heat from the casting (mould material, chill, water cooling).

The solidification rate determines the coarseness of the microstructure including the fraction, size and distribution of intermetallic phases and the segregation profiles of solute in the $\alpha$-Al phase. Large and brittle intermetallic phases form during a slow solidification, which may initiate or link fracture, decreasing elongation to fracture. Additionally, the defect size such as pore size, is also controlled to some extent by the solidification rate. The influence of defects on the elongation to fracture depends on their size, shape, distribution and fraction.

Different casting processes can be used for Al-Si alloys, as for example high and low pressure die casting and gravity casting in permanent mould or sand. HPDC has a turbulent filling and air and oxides are easily entrapped in the casting. The defect content is high, but the defects are normally small and evenly distributed, and the high solidification rate does not allow defects or intermetallic phases to grow coarse [21]. The filling in gravity casting is gentler giving a lower defect content. The defects may however be larger and have time to grow or unfurl if the solidification rate is low [21]. HPDC material normally has a low elongation to fracture due to the high defect content. Gravity cast material has a higher elongation to fracture which increases with increasing solidification rate.

\subsubsection{Post solidification treatment}

The post solidification treatment of interest for Al-Si casting alloys is heat treatment, while both cold working and heat treatment are of interest for wrought alloys. The main reason for doing a heat treatment is to obtain an increase in strength. Different heat treatment processes are available depending on the casting process and the desired properties of the alloy. A T6 heat treatment; consisting of a solution treatment, a quench and an artificial ageing, is often used for gravity cast components to achieve an increase in strength. The T6 heat treatment, which is the focus of this thesis, is discussed in more detail in the next section. The T6 heat treatment can not be used for HPDC components, as they can not be solution treated at a high temperature due to blistering. A T5 heat treatment, consisting of a fast cooling after solidification together with an artificial ageing is instead used to improve the strength. A short solution treatment prior to artificial ageing has however been shown to be successful in increasing the yield strength above that of a T5 heat treatment without occurrence of blisters $[22]$.

\subsection{THE T6 HEAT TREATMENT}

A T6 heat treatment consists of the following stages:

1. Solution treatment at a high temperature, close to the eutectic temperature of the alloy. The purpose of the solution treatment is to:

a. dissolve $\mathrm{Cu}$ - and $\mathrm{Mg}$ - rich particles formed during solidification

b. homogenize the alloying elements

c. spheroidize the eutectic Si particles.

2. Quenching, usually to room temperature, to obtain a supersaturated solid solution of solute atoms and vacancies.

3. Age hardening, to cause precipitation from the supersaturated solid solution, either at room temperature (natural ageing) or at an elevated temperature (artificial ageing). 
The T6 heat treatment is illustrated in Figure 2 for an Al-Si-Cu alloy as an example. The evolution of the microstructure is shown; from 1) atoms in solid solution at the solution treatment temperature, through 2) a supersaturated solid solution at room temperature after quench, to 3) precipitates formed at the artificial ageing temperature.

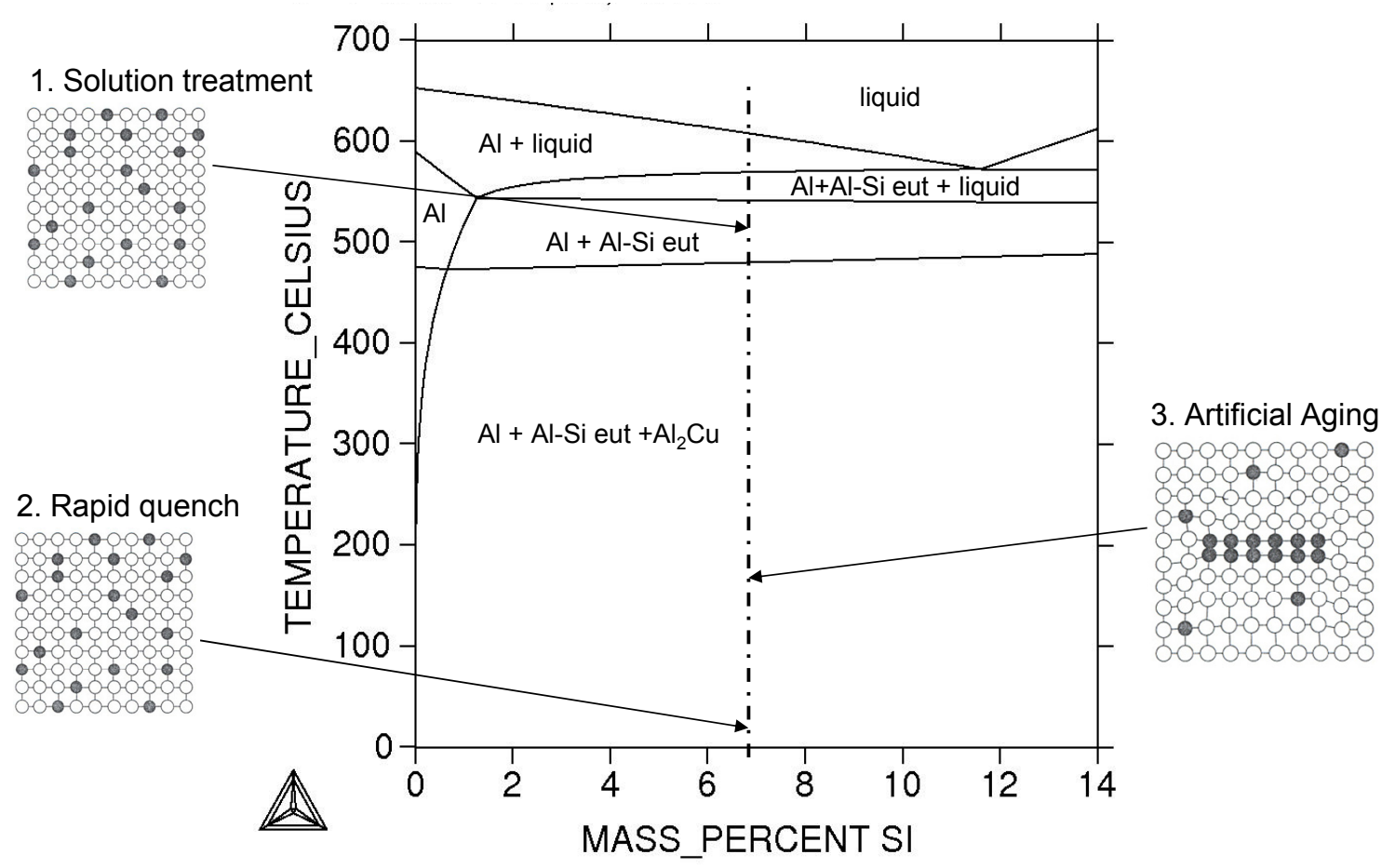

Figure 2 The T6 heat treatment process [9].

\subsubsection{Solution treatment}

The time needed for solution treatment depends on the as-cast microstructure, i.e. the size, distribution and type of intermetallic phases and the morphology of the Si particles, as well as on the temperature used. A high solution treatment temperature gives a faster dissolution, homogenization and spheroidization, and the solubility of alloying elements is higher, which will result in a higher yield strength after artificial ageing. The temperature that can be used is limited by incipient melting of phases formed from the last solidified melt that is rich in solute elements due to segregation. Localised melting results in distortion and substantially reduced mechanical properties. Cast Al-Si-Mg alloys can be solution treated at $540-550{ }^{\circ} \mathrm{C}$ [23], while alloys containing $\mathrm{Cu}$ must be solution treated at a lower temperature due to the risk of local melting of $\mathrm{Cu}$-containing phases. According to Samuel [24] Cu-containing phases start to melt at $519^{\circ} \mathrm{C}$ in an A319 alloy with low $\mathrm{Mg}$ concentration, while melting starts at $505^{\circ} \mathrm{C}$ in an $\mathrm{A} 319$ alloy with $0.5 \mathrm{wt} . \% \mathrm{Mg}$, due to the presence of the Q phase. The exact temperature that can be used without localized melting depends on the solidification rate and the heating rate to the solution treatment temperature. A two step solution treatment can be used for $\mathrm{Cu}$-containing alloys to increase strength and ductility [25]. The alloy is then first solution treated at a low temperature to dissolve $\mathrm{Cu}$-rich phases and then at a higher temperature to increase the speed of homogenisation and spheroidization.

Not all phases will dissolve during a solution treatment. The $\mathrm{Q}$ phase is reported to be stable or to dissolve very slowly for alloys having a high $\mathrm{Cu}$ concentration (3.5-4.4 wt \%) and various $\mathrm{Mg}$ concentrations when solution treated at $500^{\circ} \mathrm{C}[26,27]$. The $\pi$-Fe phase 
transforms into the $\beta$-Fe phase and $\mathrm{Mg}$ in solid solution when the $\mathrm{Mg}$ concentration is low (0.3-0.4 wt \%). The transformation does not take place or may be reversed when the $\mathrm{Mg}$ concentration is high $(0.6-0.7 \mathrm{wt} \%)[18,28]$.

\subsubsection{Quench}

The objective of quenching is to suppress precipitation upon cooling of the casting from the high solution treatment temperature to room temperature. If the quench rate is sufficiently high a high concentration of solute in solid solution and of vacancies is retained. On the other hand if the cooling is too slow, particles precipitate heterogeneously at grain boundaries or dislocations, which results in a reduction in supersaturation of solute and concomitantly a lower maximum yield strength after ageing. In Al-Si casting alloys; $\mathrm{Si}$ may diffuse from the matrix to eutectic Si particles and $\mathrm{Mg}_{2}$ Si phases may form on the eutectic Si particles or in the matrix, reducing the supersaturation of $\mathrm{Mg}$ and $\mathrm{Si}$ in the matrix [29].

The quench rate is especially critical in the temperature range between $450{ }^{\circ} \mathrm{C}$ and $200{ }^{\circ} \mathrm{C}$ for most Al-Si casting alloys where precipitates form rapidly due to a high level of supersaturation and a high diffusion rate. At higher temperatures the supersaturation is too low and at lower temperatures the diffusion rate is too low for precipitation to be critical. $4^{\circ} \mathrm{C} / \mathrm{s}$ is a limiting quench rate above which the yield strength increases slowly with further increase in quench rate [30-32].

\subsubsection{Artificial ageing}

A general and simplified precipitation sequence can be described as follows. After solution treatment and quench the matrix has a high supersaturation of solute atoms and vacancies. Clusters enriched in Si and $\mathrm{Mg}$ atoms form rapidly from the supersaturated matrix and evolve into GP zones. Metastable coherent or semi-coherent precipitates form either from the GP zones or from the supersaturated matrix when the GP zones have dissolved. The precipitates grow by diffusion of atoms from the supersaturated solid solution to the precipitates. The precipitates continue to grow in accordance with Ostwald ripening when the supersaturation is lost. The length of each step in the sequence depends on the thermal history, the alloy composition and the artificial ageing temperature.

In Al-Si-Mg alloys separate clusters of $\mathrm{Mg}$ and $\mathrm{Si}$ atoms form initially, which develop into coclusters [33]. GP zones form from the co-clusters, which elongate and transform into the $\beta$ "$\mathrm{Mg}_{5} \mathrm{Si}_{6}$ phase [33], which is the phase having the greatest strength contribution. Upon overageing some of the $\beta$ " phases transform into the rod-like $\beta$ ' phase. The Mg:Si ratio increases through the precipitation sequence $[33,34]$, which makes the supersaturation of $S i$ an important parameter as it influences the fraction of precipitates formed during initial ageing.

The precipitation sequence for Al-Si-Cu-Mg alloys is similar, but more complex, as the Q" phase and the $\theta^{\prime}$ phase may also form. Cu can increase the fraction of the $\beta$ " phase formed, but it can also form the Q" phase [35, 36], which has a lower strength contribution compared to the $\beta$ " phase. The $\beta$ " phase is therefore preferred, rather than the Q" phase. It is however not clearly stated when the Q" phase forms at the expense of the $\beta$ " phase in cast alloys. For wrought alloys it has been shown that the fraction of the Q" phase increases with natural ageing and artificial ageing time and temperature [37-39].

The precipitation sequence in $\mathrm{Al}-\mathrm{Si}$-Cu alloys is influenced by the high density of dislocations formed during quenching due to the difference in thermal expansion between the Si particles and the $\alpha$-Al matrix [40]. Fine and evenly dispersed $\theta$ " phases form in the centre of the 
dendrites, while coarse $\theta^{\prime}$ phases form on the dislocations close to the Si particles. The coarse $\theta^{\prime}$ phases have a negligible strength contribution and can be seen as a loss of $\mathrm{Cu}$ atoms that could have increased the fraction of $\theta$ " phases.

These three alloy groups show different age hardening response, which is the increase in yield strength on artificial ageing compared to the yield strength in the as-quenched or natural aged condition. The age hardening response depends on the fraction, size, distribution and coherency of precipitates formed. Al-Si-Cu-Mg alloys and $\mathrm{Al}-\mathrm{Si}-\mathrm{Mg}$ alloys generally have a high age hardening response, while $\mathrm{Al}-\mathrm{Si}-\mathrm{Cu}$ alloys have a slow and low age hardening response.

\subsection{MODELLING OF THE HEAT TREATMENT PROCESS}

Designing an alloy and a heat treatment process for a material that meets specified requirements for a certain component can be facilitated by the use of models. Development of models can also help in the search for new alloys as knowledge is gained about the influence of a specific part of the microstructure on the alloy properties. The first model where the yield strength is coupled to the evolution of the microstructure during artificial ageing was developed by Shercliff and Ashby in 1990 [41]. More refined models have been developed since then for prediction of yield strength [42-44] and elongation to fracture [45] after artificial ageing. To be able to model the tensile strength after heat treatment, the evolution of the microstructure has to be modelled from casting to artificial ageing.

\subsubsection{Modelling of the microstructure}

\subsubsection{Solidification}

The Scheil equation is a simple model giving fair results for segregation profiles and fraction of particles formed during solidification for aluminium alloys. The Scheil equation assumes no diffusion in the solid and complete diffusion in the liquid [46]. The correctness of the predictions of the Scheil segregation model depends on the diffusivity of the alloying elements in the $\alpha$-Al phase. If the diffusivity is high the model will predict a too low concentration in the matrix and a too high fraction of particles. In this case the model can be improved by including diffusion in the solid phase. In addition, much more complicated models are available in the literature [46].

\subsubsection{Solution treatment}

From the as-cast microstructure the time needed for dissolution and homogenisation can be modelled. The model developed by Rometsch et al. [47], which handles solution treatment of $\mathrm{Al}-\mathrm{Si}-\mathrm{Mg}$ alloys, is an example of a simple, but efficient model. Spherical $\mathrm{Mg}_{2} \mathrm{Si}$ particles with an interparticle distance equal to SDAS dissolve by diffusion of $\mathrm{Mg}$ into the matrix. Homogenisation within the matrix is then calculated when the particles have dissolved. The situation becomes more complicated when the number of alloying elements is increased. Models for industrial alloys have been developed by for example Dons et al. [48]. The number of phases to take into account increases and a phase diagram for the alloy system studied is needed to determine the stability and the risk of local melting of solute rich phases.

\subsubsection{Artificial ageing}

To calculate the strength after artificial ageing from the microstructure the volume fraction of precipitates and their radii need to be known, as well as the concentration of alloying elements 
in solid solution. The evolution of the microstructure during artificial ageing involves nucleation, growth and coarsening. Two main approaches are used; precipitates having an average radius or precipitates having a size distribution. For the case of precipitates with a size distribution, coupled nucleation, growth and coarsening can be calculated, while for an average radius growth is sequentially followed by coarsening.

The models by Shercliff et al. [41] and Esmaeili et al. [42] are examples of models using an average precipitate radius and where separate laws for the evolution of the volume fraction of precipitates and their average radius are used. Shercliff et al. [41] estimates the fraction of precipitates from an expression proposed by Shewmon [49] for the exponential decrease of solute concentration in the matrix. The radius of the precipitates is calculated using the Lifshitz-Slyozov-Wagner, LSW, coarsening law. Esmaeili et al. [42] calculates the fraction of precipitates from the Johson-Mehl-Avrami-Kolmogorow equation with constants derived from isothermal calorimetry. The radius of the precipitates in the underaged condition is estimated using a square root growth law with the constants derived from measurements of the precipitate radius using TEM, while the LSW coarsening law is used for the overaged condition.

The Kampmann Wagner Numerical, KWN, model treats coupled nucleation, growth and coarsening [50]. The KWN model was first applied to Al-Mg-Si alloys by Myhr et al. [43]. The basic assumptions of the model are as follows:

1) A particle distribution is used which is divided into a series of discrete size classes.

2) Nucleation is calculated and the new particles are given a radius larger than the critical radius for growth and the particles are added to the correct size class.

3) The concentration left in the matrix after nucleation is calculated using mass balance.

4) The growth or dissolution of the particles in each size class is calculated. The GibbsThomson equation is used to calculate the interface concentration, which means that the radius of the particles determines if it will dissolve or grow.

5) The particle distribution is updated using population balances.

The model takes coarsening into account naturally as small particles will start to dissolve when the concentration in the matrix becomes low. The drawback with the model is that it is very sensitive to the choice of particle-matrix interface energy and that the model is based on a constant interface energy for the whole ageing sequence, while the coherency of the precipitates in reality changes during ageing.

Models based on both approaches have been developed further, for example by taking nucleation of dislocations [51] and natural ageing [52] into account.

\subsubsection{Modelling of the tensile strength}

The strength of an alloy derives from the ability of obstacles, such as precipitates and atoms in solid solution, to hinder the motion of mobile dislocations. The strength contributions from atoms in solid solution and from shearable and non-shearable precipitates change during ageing, while contributions from lattice, dislocations and grain boundaries are constant. Superposition laws have been proposed to calculate the total strength of an alloy from the different contributions [53]. A linear superposition law, i.e. $q=1$ in eq. 1, is recommended when many soft obstacles are present (as atoms in solid solution) together with few strong obstacles (as precipitates or dislocations). A non-linear superposition law should be used for all other combinations of weak and strong obstacles [53]. The exponent $q$ varies between 1 
and 2 depending on the relative strength of the obstacles and is equal to 2 when the obstacles have similar strength.

$\sigma_{\text {tot }}=\sigma_{i}+\sigma_{s s}+\left(\sigma_{d i s}^{q}+\sigma_{p p t}^{q}\right)^{1 / q}$

All strength contributions that do not change during ageing, with the exception of that from dislocations, are included in the intrinsic strength, $\sigma_{i}$. The solid solution strengthening, $\sigma_{s,}$, depends on the concentration of solute in solid solution and on the strain field around the solute atom. The dislocation strength, $\sigma_{d i s}$, depends on the dislocation density. Dislocations form during quenching from the solution treatment temperature due to differences in thermal expansion between the Si particles and the $\alpha-\mathrm{Al}$ matrix. The largest increase in dislocation density however takes place during plastic deformation. The strength contribution of precipitates, $\sigma_{p p r}$, is determined by the volume fraction, size and distribution of the precipitates, and by the coherency of the precipitates with the matrix. Small and not too hard precipitates are normally sheared by moving dislocations, see Figure 3a. When the precipitates are larger and harder the moving dislocations pass the precipitates by bowing, leaving a dislocation ring around the precipitate, see Figure $3 \mathrm{~b}$. The strength of the precipitates increases with size as long as it is sheared by dislocations. When dislocations pass the precipitates by looping, the alloy strength decreases with increasing radius of the precipitates. Figure $3 \mathrm{c}$ shows the different strength contributions to the total yield strength for different ageing times.
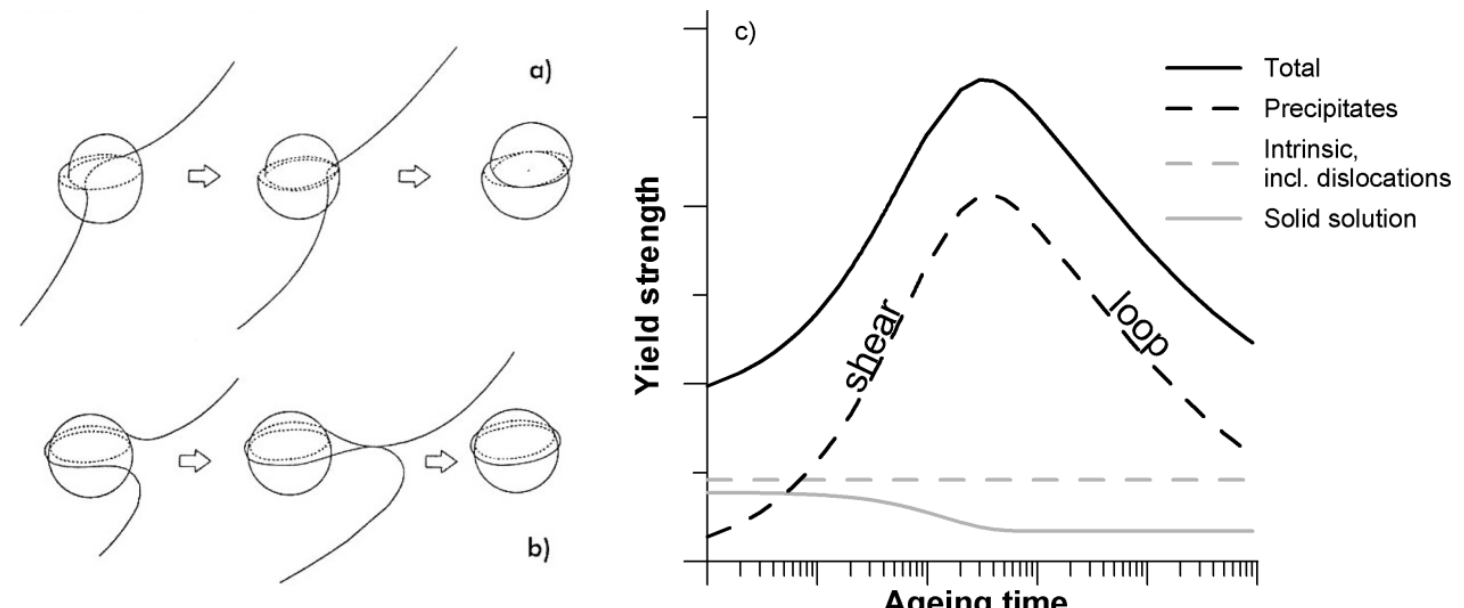

Figure 3 Dislocations passing a precipitate by a) shearing and b) looping (Orowan mechanism) [54] c) Illustrates the different strength contributions to the total yield strength

Different equations can be used to describe the plastic part of the stress-strain curve. Some are empirical, as the Hollomon [55] and Ludwigson [56] equations, while others have a physical background, as the Kocks-Mecking, KM, strain hardening theory [57-59]. The Hollomon equation is given by eq. 2 . where $\sigma$ is the true stress, $\varepsilon_{p}$ the true plastic strain, $K_{1}$ a material constant and $n_{1}$ the strain hardening exponent. The Ludwigson equation, eq. 3 , is based on the Hollomon equation, but has a correction term for small strains.

$\sigma=K_{1} \varepsilon_{p}^{n_{1}}$

$\sigma=K_{1} \varepsilon_{p}^{n_{1}}+\exp \left(K_{2}+n_{2} \varepsilon_{p}\right)$

The KM strain hardening theory is based on the evolution of the dislocation density, $\rho$, during plastic deformation and their contribution to strength, $\sigma_{d i s}$. The KM strain hardening theory is divided into four stages [58]. Stage I, single slip, occurs only in single crystals. Stage II is a pure hardening due to an increase in dislocation density. Stage III starts when 
annihilation or rearrangement of dislocations start to occur. A linear decrease in strain hardening rate is observed for Stage III, see Figure 4. Stage IV occurs after necking. In a pure metal the dislocation density increases during plastic deformation due to interactions between dislocations. The evolution of the dislocation density with strain for pure metals for Stage III strain hardening is described by eq. 4 , where $M$ is the Taylor factor. The first term is associated with storage of mobile dislocations due to interaction with forest dislocations, where $\rho^{-1 / 2}$ is proportional to the mean free path of dislocations. The second term is associated with dynamic recovery due to annihilation or rearrangement of dislocations. The contribution from the dislocation density to strength is given in eq. 5, where $\alpha$ is a constant, $G_{\alpha}$ the shear modulus of the $\alpha-\mathrm{Al}$ phase and $b$ the magnitude of the Burgers vector.

$$
\begin{aligned}
& \frac{\partial \rho}{\partial \varepsilon_{p}}=M\left(k_{1} \sqrt{\rho}-k_{2} \rho\right) \\
& \sigma_{d i s}=\alpha M G_{\alpha} b \sqrt{\rho}
\end{aligned}
$$

The strain hardening rate, $\theta$, given in eq. 6 can be derived from eq. 4 and eq. 5 for pure metals which obey a linear superposition law. $\theta_{0}=\alpha M^{2} G b k_{I} / 2$ is related to the dislocation storage rate, $K=M k_{2} / 2$ is related to the recovery rate and $\sigma_{Y S}$ is the yield strength.

$\theta=\frac{d \sigma}{d \varepsilon_{p}}=\theta_{0}-K\left(\sigma-\sigma_{Y S}\right)$

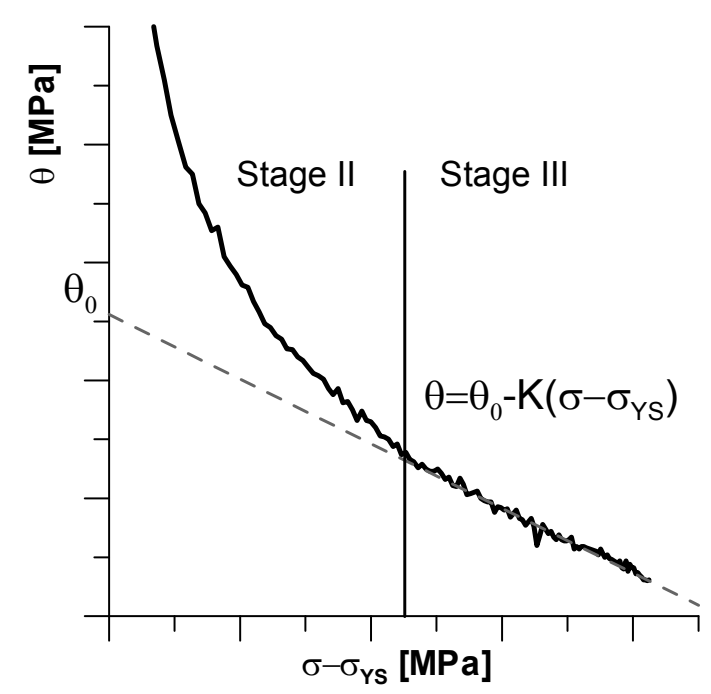

Figure 4 Change in strain hardening rate with reduced flow stress (experimental curve).

In $\mathrm{Al}-\mathrm{Si}$ casting alloys containing $\mathrm{Cu}$ and/or $\mathrm{Mg}$ the situation becomes more complex as $\mathrm{Cu}$ and $\mathrm{Mg}$ atoms can be present in solid solution, as shearable precipitates or as non-shearable precipitates, all interacting with the moving dislocations. These interactions will influence both the storage rate and recovery rate of dislocations affecting the plastic deformation behaviour of the alloy. When non-coherent precipitates are present eq. 4 must be modified as the mean free path of the dislocations is reduced. The storage of dislocations at non-coherent precipitates is introduced in the model, see eq. 7 , by adding a constant term $k_{D}=(b d)^{-1}$ to eq. 4 , where $d$ is the distance between the precipitates [57]. Further, a non-linear superposition law should be used when non-coherent precipitates and dislocations are present.

$\frac{\partial \rho}{\partial \varepsilon_{p}}=M\left(k_{1} \sqrt{\rho}-k_{2} \rho+k_{D}\right)$ 


\section{RESEARCH APPROACH}

\subsection{AIM AND PURPOSE OF THE WORK}

The requirements on reduced emissions from vehicles have sharpened and forced the automotive industry to search for new solutions. One way to reduce the emissions is to decrease the weight of the vehicle, which will reduce the fuel consumption. A lighter vehicle also means that a smaller engine can be used, leading to a further reduction in weight. Al-Si casting alloys are of considerable interest for the automotive industry due to their high strength to weight ratio and high thermal conductivity.

Al-Si casting alloys are well studied and there exists a lot of knowledge about the influence of alloying elements and solidification rate on the microstructure formation. The influence of heat treatment on hardness and yield strength is also well studied, while the influence on the plastic deformation behaviour and elongation to fracture is less studied. The tensile properties of a component can be simulated for the as-cast condition using commercial casting simulation software. The tensile properties for the heat treated condition can however not be simulated, but equations valid for certain alloys have been developed. The aim of this work is to be able to model tensile properties after heat treatment for alloys with chemical compositions within certain limits taking the as-cast microstructure into account. This work focus on solution treatment and artificial ageing, assuming that the quench is rapid and that no natural ageing takes place between quench and artificial ageing.

\subsection{RESEARCH QUESTIONS}

To be able to model the tensile properties in the heat treated condition, knowledge about the whole chain from solidification to artificial ageing is needed. Experimental work is needed despite the fact that there is a lot of data available in the literature. In some cases, information is missing and in other cases it is necessary to produce independent data to have full knowledge of all the process parameters. In order to model the tensile properties in the heat treated condition several questions need to be answered to be able to model each process involved in this chain. Some of the questions are raised below.

Solidification (Supplements I, II \& III)

How does the solidification rate influence:

a. the type of phases formed?

b. the distribution of $\mathrm{Mg} / \mathrm{Cu}$ rich phases?

c. the segregation profiles of solutes in the $\alpha$-Al matrix?

This knowledge about the as-cast microstructure is needed as it defines the initial condition for the solution treatment model. Information is available in the literature regarding the phases formed during solidification and in some cases also on how the 
solidification rate influences the type and fraction of phases formed. However it is not well-known how the phases are distributed in the microstructure. The influence of the solidification rate on the segregation profiles of alloying elements is not well studied and there is scatter in the results presented.

Solution treatment (Supplements I, II \& III)

Which phases are stable at the solution treatment temperature and which will dissolve or transform?

Phase diagrams offer information about the stability of phases and the solubility of alloying elements. Phase diagrams which are able to predict the solubility limit of the alloying elements are a necessity when modelling the solution treatment. No general study of phase diagrams was done, rather a check if the phase diagrams derived by ThermoCalc [9] can be used for the alloys of interest in the present study.

$>$ How does the coarseness of the microstructure influence the time needed for dissolution and homogenisation?

$>$ Is the solution treatment process diffusion or interface controlled?

$>$ Is the diffusion of one alloying element influenced by the fact that it is diffusing in a concentration gradient of other alloying elements?

These questions need to be answered to develop a model for solution treatment. The concentration increase of solute in the matrix during solution treatment has earlier been studied for $\mathrm{Al}-\mathrm{Si}-\mathrm{Mg}$ alloys, but no systematic measurements have been done for $\mathrm{Al}-\mathrm{Si}-\mathrm{Cu}$ and $\mathrm{Al}-\mathrm{Si}-\mathrm{Cu}-\mathrm{Mg}$ alloys. Further, no investigations where the coarseness of the microstructure has been varied have been found. The concentration increase for the different coarsenesses of the microstructure can be used to determine whether the solution treatment process is diffusion controlled or not. The concentration increase in the matrix for different alloys can be compared to determine if the diffusivity of one alloying elements is affected by the presence of the other.

Artificial ageing (Supplements I, IV V \& VI)

$>$ Which parameters determine the shape of the ageing curves?

The microstructure evolution during artificial ageing is difficult to follow as the precipitates formed are only a few nanometres in size and must be studied using TEM. It is however possible to study the yield strength that the precipitates cause and try to identify the mechanisms determining the appearance of the ageing curves. Available literature data was compared in the search for these mechanisms. There is however a large number of parameters that can be varied which will influence the shape of the ageing curves. Tensile tests after artificial ageing were performed to obtain data sets for which all process parameters are known. These data sets are compared with the data presented in the literature.

Modelling of the microstructure evolution during artificial ageing raises a large number of questions for example, i) the composition, morphology and surface energy of the precipitates, ii) the influence of excess vacancies on the diffusivity of $\mathrm{Mg}$, iii) the need for a metastable solvus boundary and iv) the number density of precipitates formed. The answers to these questions have been searched for in the literature.

How is the yield strength composed? 
In order to model the yield strength from the artificially aged microstructure different strengthening laws need to be identified and evaluated. A superposition law for the different strength contributions also need to be decided on.

$>$ How does artificial ageing influence the plastic deformation behaviour and the elongation to fracture?

To be able to model the plastic part of the stress-strain curve more knowledge is needed about the influence of the microstructure on the formation and annihilation of dislocations which determine the plastic deformation behaviour. The influence of artificial ageing on the plastic deformation and elongation to fracture has earlier been studied for $\mathrm{Al}-\mathrm{Si}-\mathrm{Mg}$ alloys, but no investigations have been done for $\mathrm{Al}-\mathrm{Si}-\mathrm{Cu}$ and $\mathrm{Al}-\mathrm{Si}-\mathrm{Cu}-\mathrm{Mg}$ alloys.

Which model is most suitable to describe the plastic deformation behaviour?

Empirical equations as the Hollomon's and the Ludwigson's and equations where the parameters are coupled to the microstructure as in the KM strain hardening theory can be used to describe the plastic deformation behaviour. The KM strain hardening theory has already been successfully used to couple the plastic deformation behaviour to the microstructure for heat treatable wrought alloys and an $\mathrm{Al}-\mathrm{Si}-\mathrm{Mg}$ casting alloy. It is therefore of interest to investigate if this hardening theory can also be used for different Al-Si casting alloys.

\subsection{MATERIAL AND EXPERIMENTAL PROCEDURE}

\subsubsection{Alloys and solidification rates}

This work is mainly based on three alloys (1-3 in Table 1). Alloy 1 is an A356 master alloy. Alloy 2 was produced from pure $\mathrm{Al}, \mathrm{Si}$ and $\mathrm{Cu}$. Alloy 3 was produced from an $\mathrm{Al}-9 \mathrm{Si}-1 \mathrm{Cu}$ master alloy with additions of pure $\mathrm{Al}, \mathrm{Cu}$ and $\mathrm{Mg}$. Alloys 2 and 3 were grain refined using an $\mathrm{Al}-\mathrm{Ti}-5 \mathrm{~B}$ master alloy. A second casting trial was done for the Al-Si-Mg alloy ( 4 in Table 1 ) as more material was needed. Alloy 4 is based on pure $\mathrm{Al}, \mathrm{Si}$ and $\mathrm{Mg}$. All alloys (1-4) were $\mathrm{Sr}$ modified using an $\mathrm{Al}-10 \mathrm{Sr}$ master alloy.

Table 1 Alloy composition in wt\%.

\begin{tabular}{lccccccc}
\hline & $\mathbf{S i}$ & $\mathbf{C u}$ & $\mathbf{M g}$ & $\mathbf{F e}$ & $\mathbf{T i}$ & $\mathbf{A l}$ & $\mathbf{S r}(\mathbf{p p m})$ \\
\hline 1. Al-Si-Mg & 7.1 & 0.0 & 0.33 & 0.11 & 0.13 & Bal. & 351 \\
2. Al-Si-Cu & 7.8 & 3.1 & 0.00 & 0.12 & 0.13 & Bal. & 352 \\
3. Al-Si-Cu-Mg & 8.5 & 3.1 & 0.47 & 0.17 & 0.23 & Bal. & 350 \\
\hline 4. Al-Si-Mg & 7.8 & 0.0 & 0.40 & 0.09 & 0.01 & Bal. & 391 \\
\hline
\end{tabular}

Cylindrical rods (length $18 \mathrm{~cm}$, diameter $1 \mathrm{~cm}$ ) were cast in a permanent mould, PM, preheated to $200^{\circ} \mathrm{C}$. The rods were remelted with the gradient solidification technique. The gradient solidification equipment is shown in Figure 5. The PM cast rods were inserted into the furnace at $710^{\circ} \mathrm{C}$ where they were remelted for $20 \mathrm{~min}$. The furnace was then raised at a prescribed speed and the samples were withdrawn from the furnace. Water cooling beneath the furnace was used for high furnace speeds to cool the samples. The speed of the furnace determines the solidification rate of the samples. Different microstructures can thereby be produced by changing the speed of the furnace. Three different coarsenesses of the 
microstructure, having SDAS of approximately 10, 25 and $50 \mu \mathrm{m}$, were produced for the present investigation. The samples produced using the gradient solidification technique have a low defect content. The solidification is directional, giving a good feeding and gas and oxides are pushed ahead of the solidification front. Samples for chemical composition measurements were cast just before casting the cylindrical rods. The chemical composition was measured using an optical emission spectrometer, OES.

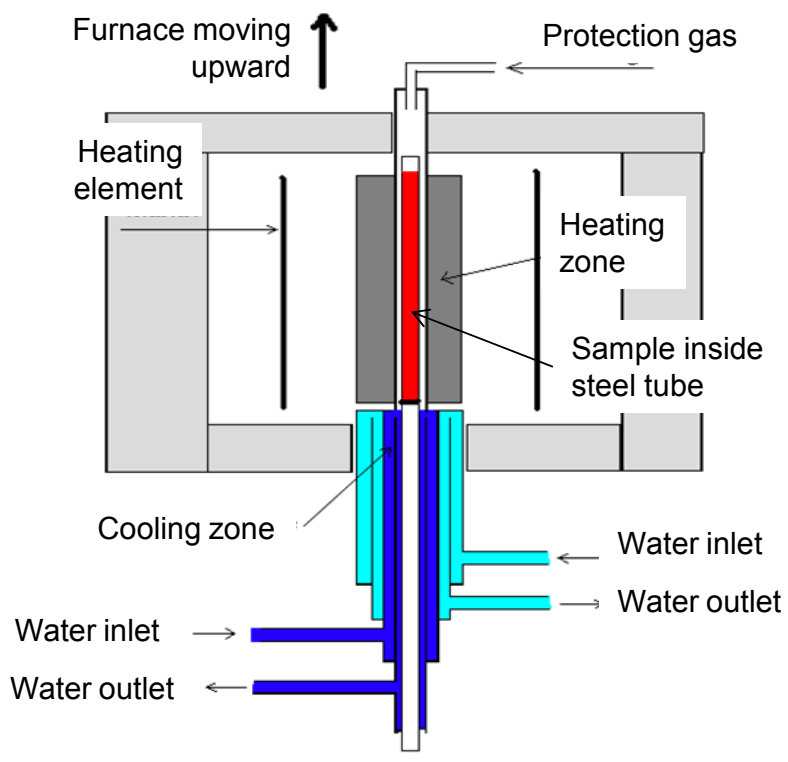

Figure 5 The gradient solidification equipment.

\subsubsection{Solution treatment}

Solution treatment was conducted in an electrical furnace at a temperature of $530^{\circ} \mathrm{C}$ for the $\mathrm{Al}-\mathrm{Si}-\mathrm{Mg}$ alloy and at $495^{\circ} \mathrm{C}$ for the $\mathrm{Cu}$-containing alloys. The time for heating the samples to the solution treatment temperature was $10-15 \mathrm{~min}$. and is excluded from the presented times. Times from $10 \mathrm{~min}$. up to $10 \mathrm{~h}$ were used for the solution treatment studies. Times thought to be long enough to ensure complete dissolution and homogenization of alloying elements were used for the artificial ageing studies. Times of $1 \mathrm{~h}, 3 \mathrm{~h}$ and $6 \mathrm{~h}$ were used for SDAS 10, 25 and $50 \mu \mathrm{m}$, respectively, for all three alloys. The samples were quenched in $50^{\circ} \mathrm{C}$ water.

\subsubsection{Artificial ageing}

The samples were naturally aged at room temperature for 1 day prior to artificial ageing, which was conducted in a forced circulation air furnace at $170^{\circ} \mathrm{C}$ or $210^{\circ} \mathrm{C}$ for various times. The time needed for heating the samples to the artificial ageing temperature was $20 \mathrm{~min}$. and is excluded from the presented times. The samples were taken out of the furnace and cooled in still air after artificial ageing.

\subsubsection{Tensile testing}

The artificially aged samples were tensile tested. Tensile test bars with a gauge length of 50 $\mathrm{mm}$ and a diameter of $7 \mathrm{~mm}$ were machined from the rods prior to heat treatment. Tensile tests were performed at a constant strain rate of $0.5 \mathrm{~mm} / \mathrm{min}$ using a Zwick/Roell Z100 machine equipped with a $100 \mathrm{kN}$ load cell and a clip-on $25 \mathrm{~mm}$ gauge length extensometer. 
The extensometer was applied until fracture of the samples. Two tensile test bars were tested for each heat treatment condition.

\subsubsection{Microstructure evaluation}

The microstructure of as-cast samples was studied using a scanning electron microscope, SEM. The area fraction of intermetallic phases, SDAS, the distance between $\mathrm{Mg} / \mathrm{Cu}$ rich particles and the length of intermetallic phases were measured for the as-cast samples. The areas investigated were normalized to the coarseness of the microstructure and were chosen to cover the same numbers of dendrites on each frame. The areas were also adjusted to the alloy, depending on the size of the intermetallic phases. 30 frames having an area of 7.3SDAS $x$ 5.7SDAS were used for the $\mathrm{Cu}$ containing alloys and 80 frames having an area of 2.7SDAS $\mathrm{x}$ 2.1SDAS were used for the Al-Si-Mg alloy. The following number of measurements was used: 40 measurements for SDAS, 50 measurements for the distance between $\mathrm{Mg} / \mathrm{Cu}$ rich phases and 30 measurements for the length of the intermetallic phases. Fracture surfaces of artificially aged samples were studied using SEM, and energy dispersive spectroscopy, EDS.

\subsubsection{Concentration measurements}

The concentrations of $\mathrm{Mg}, \mathrm{Cu}$ and $\mathrm{Si}$ in the $\alpha$-Al matrix after solution treatment and quenching were measured using wavelength dispersive spectroscopy, WDS. Measurements were made over dendrite arms situated far from $\mathrm{Cu}$ and $\mathrm{Mg}$ rich phases. A minimum of 10 points per sample were measured. The points were situated either on the side or in the centre of the dendrite arms. The acceleration voltage was set to $20 \mathrm{kV}$ for $\mathrm{Cu}$ and $10 \mathrm{kV}$ for $\mathrm{Mg}$ and Si measurements and pure elements were used as standards. Dwell times were set to achieve about 600 counts above the background counts at the peak energy for the element of interest. Measuring the $\mathrm{Cu}$ peak is very time consuming and an equation was derived to decrease the analysis time. A reduced scan was done for 50 points in the $\alpha-\mathrm{Al}$ matrix having concentrations in the range 0.8-3.9 wt $\% \mathrm{Cu}$. The collected spectra were quantified and a relation between the quantified concentrations and the maximum counts was derived. For the rest of the measurement points in the dendrite arms 15 channels around the peak energy were measured and the highest count obtained was used to calculate the concentration with the experimentally derived equation.

EDS measurements were used to identify Fe-containing phases in the as-cast condition and to follow their evolution during solution treatment. 
RESEARCH APPROACH 


\section{SUMMARY OF RESULTS AND DISCUSSION}

\subsection{INFLUENCE OF SOLIDIFICATION RATE AND ALLOYING ELEMENTS ON THE AS-CAST MICROSTRUCTURE (SUPPLEMENTS II AND III)}

The solidification rate and the alloying elements determine the as-cast microstructure, i.e. 1) the coarseness of the microstructure, 2) the segregation profiles of alloying elements in the $\alpha$ $\mathrm{Al}$ matrix and 3) the type, size and distribution of the intermetallic particles.

\subsubsection{Coarseness of the microstructure}

SDAS is often used as a measure of the coarseness of the microstructure. The relationship between the solidification rate and the coarseness of the microstructure, SDAS, is well studied in the literature, and is not the focus of the present study. The average measured SDAS and standard deviations within brackets for the investigated alloys are presented in Table 2. A small influence of the amount of alloying elements on the SDAS can be observed. The solute lean $\mathrm{Al}-\mathrm{Si}-\mathrm{Mg}$ alloy has a slightly higher SDAS compared to the alloy containing $3 \mathrm{wt} \% \mathrm{Cu}$, which is in agreement with data reported by Shabestari [60].

Table 2 As-cast parameters of the microstructure; SDAS and length of the largest intermetallic particles. Standard deviations within brackets.

\begin{tabular}{|c|c|c|c|c|c|c|}
\hline \multirow[b]{2}{*}{ Alloy } & \multirow{2}{*}{$\begin{array}{c}\text { sol. } \\
\text { rate } \\
{[\mathrm{mm} / \mathrm{s}]}\end{array}$} & \multirow[b]{2}{*}{$\begin{array}{l}\text { SDAS } \\
{[\mu \mathrm{m}]}\end{array}$} & \multicolumn{4}{|c|}{ Length of particles ${ }^{a}$} \\
\hline & & & $\begin{array}{l}\mathrm{Al}_{2} \mathrm{Cu} \\
{[\mu \mathrm{m}]}\end{array}$ & $\begin{array}{c}\text { Fe rich } \\
{[\mu \mathrm{m}]}\end{array}$ & $\begin{array}{c}\mathrm{Si} \\
{[\mu \mathrm{m}]}\end{array}$ & $\begin{array}{c}Q \\
{[\mu \mathrm{m}]}\end{array}$ \\
\hline \multirow[t]{3}{*}{ Al-Si-Mg } & 0.03 & $51(7)$ & & $31(20)$ & $22(7)$ & \\
\hline & 0.3 & $28(3)$ & & $14(9)$ & $8(2)$ & \\
\hline & 3 & $10(1)$ & & $3(1)$ & $2(1)$ & \\
\hline \multirow[t]{3}{*}{$\mathrm{Al}-\mathrm{Si}-\mathrm{Cu}$} & 0.03 & $50(6)$ & $193(86)$ & $109(29)$ & $44(11)$ & \\
\hline & 0.3 & $25(4)$ & $57(20)$ & $41(16)$ & $12(3)$ & \\
\hline & 3 & $10(2)$ & $8(3)$ & - & $2(1)$ & \\
\hline \multirow[t]{3}{*}{ Al-Si-Cu-Mg } & 0.03 & $49(7)$ & $107(41)$ & $87(28)$ & $28(8)$ & $40(24)$ \\
\hline & 0.3 & $24(3)$ & $30(10)$ & $24(11)$ & $10(2)$ & $11(8)$ \\
\hline & 3 & $9(1)$ & & & $3(1)$ & \\
\hline
\end{tabular}

${ }^{\mathrm{a}}$ The phases in the Al-Si-Cu-Mg alloy having the finest microstructure were too small and close to each other to distinguish the different phases. 


\subsubsection{Segregation profiles of alloying elements}

The influence of the solidification rate on the segregation profiles of $\mathrm{Si}, \mathrm{Mg}$ and $\mathrm{Cu}$ in the $\alpha$ Al matrix is less studied in the literature. The concentration profiles for Si for different solidification rates have been studied by Pedersen et al. [61]. An anomalous segregation profile was observed, with higher Si concentration in the centre of the dendrite arm compared to the edges, for alloys solidified slowly. Dons et al. [62] showed that the anomalous segregation profile for Si was caused by diffusion of Si from the $\alpha$-Al matrix to Si particles in the Al-Si eutectic after solidification. Anomalous segregation profiles for Si were confirmed by the present investigation for the two slower solidification rates for all three alloys, see Figure 6a. The segregation profiles for $\mathrm{Mg}$ and $\mathrm{Cu}$ are shown in Figure 6b-c for the ternary alloys. The $\mathrm{Mg}$ concentration in the centre of the dendrite arm increases with decreasing solidification rate. Back diffusion during solidification and cooling results in an increase in $\mathrm{Mg}$ concentration in the centre of dendrite arms at slow solidification rates. The diffusivity for $\mathrm{Cu}$ in the $\alpha-\mathrm{Al}$ phase is lower compared to $\mathrm{Mg}$ and the influence of back diffusion is less pronounced, see Figure 6c. The segregation profiles of the Al-Si-Cu-Mg alloy are similar to the ones for the ternary alloys presented in Figure 6a-c. Diffusion of $\mathrm{Mg}$ and $\mathrm{Cu}$ in the $\alpha-\mathrm{Al}$ phase is apparently not influenced by the concentration gradient of the other solute element.

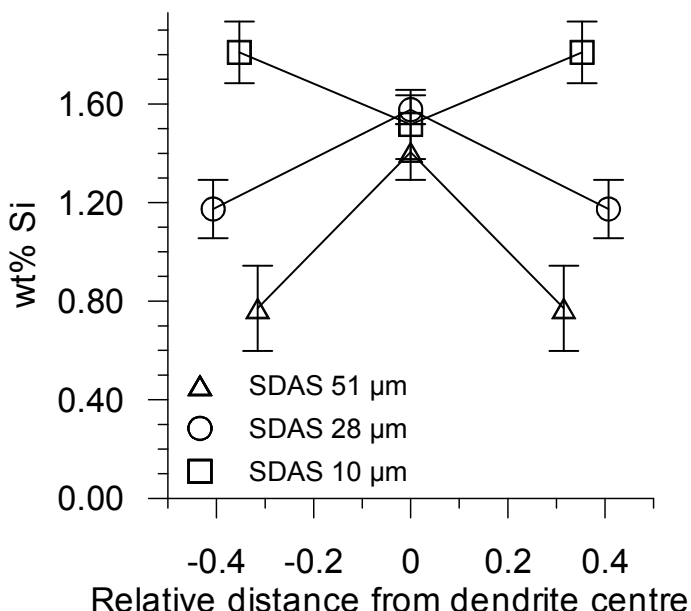

(a)

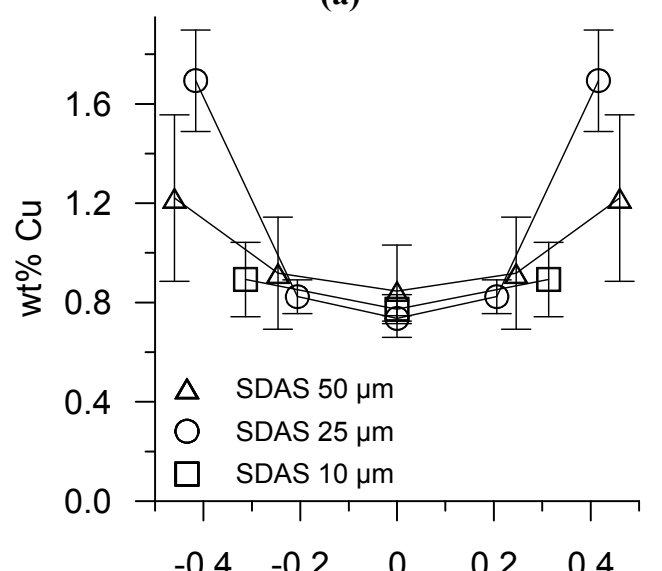

Relative distance from dendrite centre

(c)

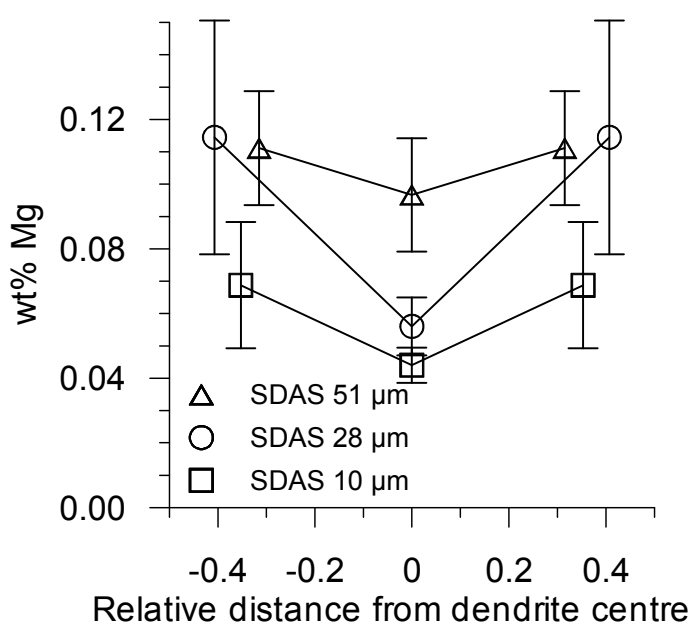

(b)

Figure 6 As-cast concentration profiles. a) Si and b) Mg for the Al-Si-Mg alloy and c) Cu for the Al-SiCu alloy. 
A small number of articles present segregation profiles for $\mathrm{Cu}$ and $\mathrm{Mg}$ in the $\alpha$-Al dendrites. The presented $\mathrm{Cu}$ concentrations in the centre of the dendrite arms show some variations and values of $1.2 \mathrm{wt} \%$ [63] and $0.6 \mathrm{wt} \%$ [64] are reported for an Al-7Si-3.5Cu alloy. The consistency in reported data is better for $\mathrm{Mg}[61,65]$ and is in line with data from the present investigation. Possible reasons for deviations in the reported results in the literature are differences in measurement method used, EDS or WDS, and the difficulty of finding a dendrite that is cut through its centre. None of the reported studies show as detailed measurements of $\mathrm{Cu}$ and $\mathrm{Mg}$ segregation profiles as the ones reported in the present investigation.

\subsubsection{Type, size and distribution of intermetallic particles}

The $\pi$-Fe phase is the main phase containing $\mathrm{Mg}$ in the Al-Si-Mg alloy for all three solidification rates, although a small amount of $\mathrm{Mg}_{2} \mathrm{Si}$ was observed in the coarsest microstructure. The area fraction of the $\pi$-Fe phase increases, while the fraction of the $\beta$-Fe phase decreases with increasing solidification rate, see Figure $7 \mathrm{a}$. The $\pi$-Fe phases are small and uniformly distributed in the finest microstructure, while they are present as large script in the two coarser microstructures. The $\mathrm{Al}_{2} \mathrm{Cu}$ phase is the main phase containing $\mathrm{Cu}$ in the $\mathrm{Al}$ $\mathrm{Si}-\mathrm{Cu}$ and $\mathrm{Al}-\mathrm{Si}-\mathrm{Cu}-\mathrm{Mg}$ alloys. In the coarsest microstructure the $\mathrm{Al}_{2} \mathrm{Cu}$ particles are large and situated far from each other, mostly in regions far from the well-modified Si eutectic. Their distribution is more homogenous for the finer microstructures and small individual $\mathrm{Al}_{2} \mathrm{Cu}$ particles form on the well-modified eutectic Si particles. In the finest microstructure there are no regions that are without $\mathrm{Al}_{2} \mathrm{Cu}$ particles. The fraction of the $\mathrm{Al}_{2} \mathrm{Cu}$ particles increases with increasing solidification rate, see Figure $7 \mathrm{~b}$. The $\mathrm{Q}$ phase forms in addition to the $\mathrm{Al}_{2} \mathrm{Cu}$ phase in the $\mathrm{Al}-\mathrm{Si}-\mathrm{Cu}-\mathrm{Mg}$ alloy. For the coarsest microstructure the $\mathrm{Q}$ phase is present either as large independent particles or in a complex eutectic with $\mathrm{Si}$ and $\mathrm{Al}_{2} \mathrm{Cu}$ phases. The fraction of large independent $Q$ phases decreases when the solidification rate increases. The length of the intermetallic phases for the different solidification rates is presented in Table 2.

The distances between phases containing the largest concentrations of $\mathrm{Cu}$ and $\mathrm{Mg}$ are presented in Figure 7c. The solidification rate has a large influence on the distance between the phases, while alloy composition has a smaller influence. The distance between the phases is larger than the SDAS for the two coarser microstructures. A comparison of solution treatment results with data from the literature for gravity cast Al-Si-Mg alloys [65, 66] indicated that the phases have a finer distribution in gravity cast material compared to the gradient cast material used in the present investigation. The solidification behaviour, being directional for gradient solidification and mainly equiaxed for gravity casting, is believed to be the reason for the difference. 


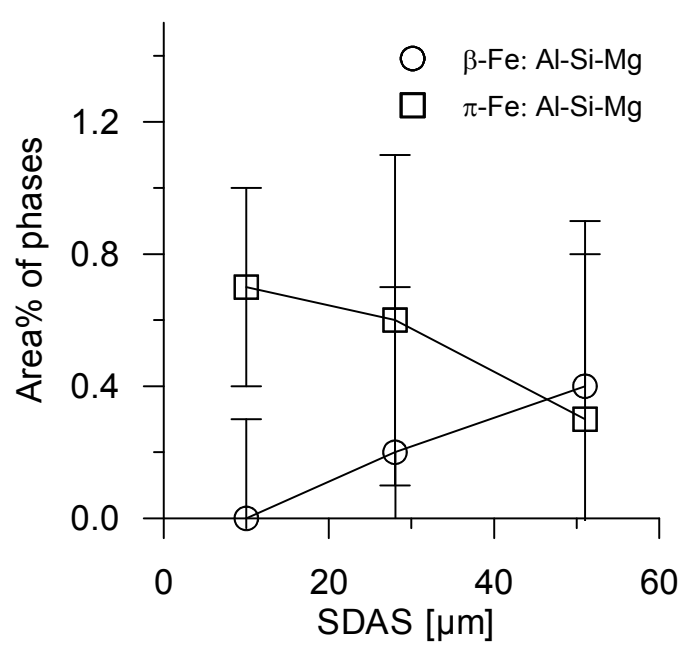

(a)

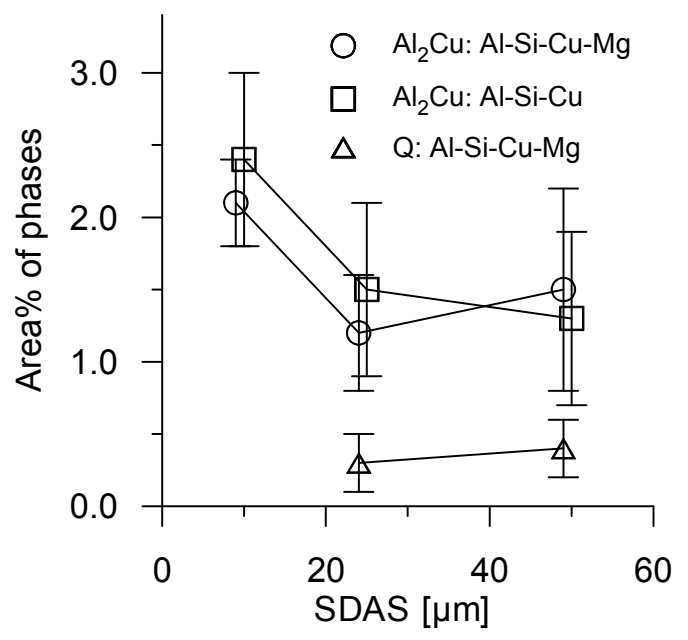

(b)

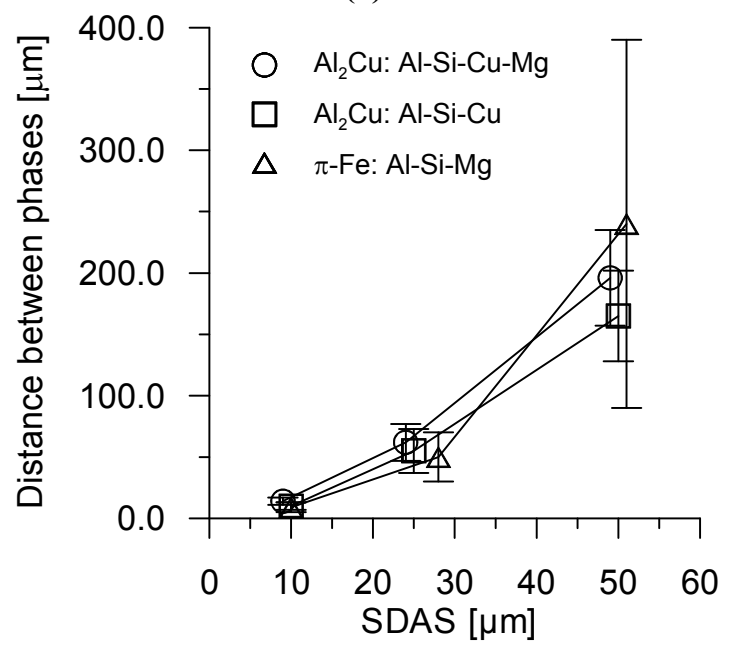

(c)

Figure 7 As-cast parameters of the microstructure; Area\% of phases a) in the Al-Si-Mg alloy and b) in the $\mathrm{Al}-\mathrm{Si}-\mathrm{Cu}$ and $\mathrm{Al}-\mathrm{Si}-\mathrm{Cu}-\mathrm{Mg}$ alloys. The $\mathrm{Q}$ phase and the $\mathrm{Al}_{2} \mathrm{Cu}$ phase could not be measured separately for the finest microstructure of the Al-Si-Cu-Mg alloy. c) Distance between $\mathrm{Mg} / \mathrm{Cu}$ rich phases.

\subsection{INFLUENCE OF THE AS-CAST MICROSTRUCTURE ON THE SOLUTION TREATMENT RESPONSE (SUPPLEMENTS II AND III)}

The results of the dissolution and homogenization process depend on the coarseness of the microstructure (.i.e. the diffusion distance), the type of diffusing elements and the stability of phases in combination with the temperature and time used. In the present study the influence of time, coarseness of the microstructure and diffusing elements is investigated. The coarseness of the microstructure is known to influence the time needed for dissolution and homogenisation. In some articles both alloy and coarseness of the microstructure is varied [27, 47], but no experiments have been found where SDAS is varied for a certain alloy.

The time needed for dissolution and homogenization depends strongly on the coarseness of the microstructure. For the $\mathrm{Cu}$ containing alloys, $10-30 \mathrm{~min}$ at $495^{\circ} \mathrm{C}$ was sufficient to achieve complete dissolution and homogenisation for the finest microstructure (Figure 8a), while more than $10 \mathrm{~h}$ was needed for the coarsest microstructure (Figure 8c), as undissolved $\mathrm{Al}_{2} \mathrm{Cu}$ particles still remained after $10 \mathrm{~h}$. The long time needed for a coarse microstructure is in agreement with the literature, where $8-12 \mathrm{~h}$ at $490-505^{\circ} \mathrm{C}$ is reported for alloys having $3-4$ 
wt $\% \mathrm{Cu}$ and SDAS of 40-60 $\mu \mathrm{m}$ [26, 67-69]. In the Al-Si-Cu-Mg alloy the Q phase, which forms during solidification, is observed to be stable at $495^{\circ} \mathrm{C}$. The presence of a stable $\mathrm{Q}$ phase has a minor influence on the $\mathrm{Cu}$ concentration, but a major influence on the $\mathrm{Mg}$ concentration. The $\mathrm{Mg}$ concentration reaches about $0.22-0.25 \mathrm{wt} \%$ where it remains stable for long solution treatment times, see Figure 9b. This observation is in agreement with the literature where the $\mathrm{Q}$ phase is reported to be stable or slow dissolving at $500^{\circ} \mathrm{C}$ for alloys having a high $\mathrm{Cu}$ concentration (3.5-4.4 wt \%) and various $\mathrm{Mg}$ concentrations [26, 27].

The homogenisation and dissolution process of the Al-Si-Mg alloy is faster than for the $\mathrm{Cu}$ containing alloys due to the higher temperature that can be used and the faster diffusivity of $\mathrm{Mg}$ compared to $\mathrm{Cu}$ in the $\alpha$ - $\mathrm{Al}$ phase. The $\pi$-Fe phase transforms into the $\beta$-Fe phase and $\mathrm{Mg}$ in solid solution when solution treated at $530^{\circ} \mathrm{C}$ and the concentration of $\mathrm{Mg}$ in the matrix increases rapidly, which is in agreement with literature $[18,28]$. Complete dissolution and homogenisation is obtained after $30 \mathrm{~min}$. for the two finest microstructures (Figure 8d-e), while about $10 \mathrm{~h}$ is needed for the coarsest microstructure (Figure $8 \mathrm{f}$ ).

A high and homogenous Si concentration after solution treatment is important for the Al-Si$\mathrm{Mg}$ and $\mathrm{Al}-\mathrm{Si}-\mathrm{Cu}-\mathrm{Mg}$ alloys as the $\beta "\left(\mathrm{Mg}_{2} \mathrm{Si}\right)$ phase forms during artificial ageing. Homogenization of $\mathrm{Si}$ is faster than for $\mathrm{Mg}$ and $\mathrm{Cu}$ and does not determine the time needed to achieve complete dissolution and homogenization. As an example; a homogeneous concentration in the dendrites of 1.1-1.2 wt \% Si, close to the equilibrium value of $1.06 \mathrm{wt} \%$ $\mathrm{Si}$ at $530^{\circ} \mathrm{C}$ [9], is reached after $10 \mathrm{~min}$. for the finest microstructure and after $30 \mathrm{~min}$. for the two coarser ones for the Al-Si-Mg alloy.

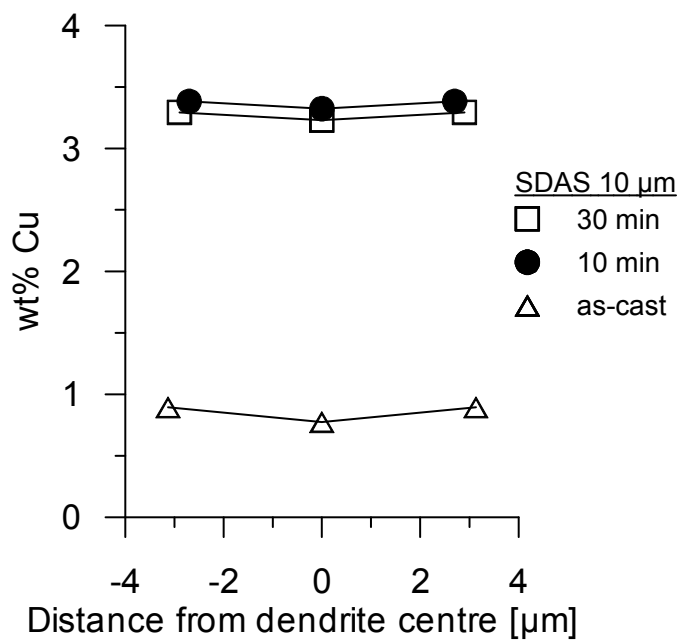

(a)

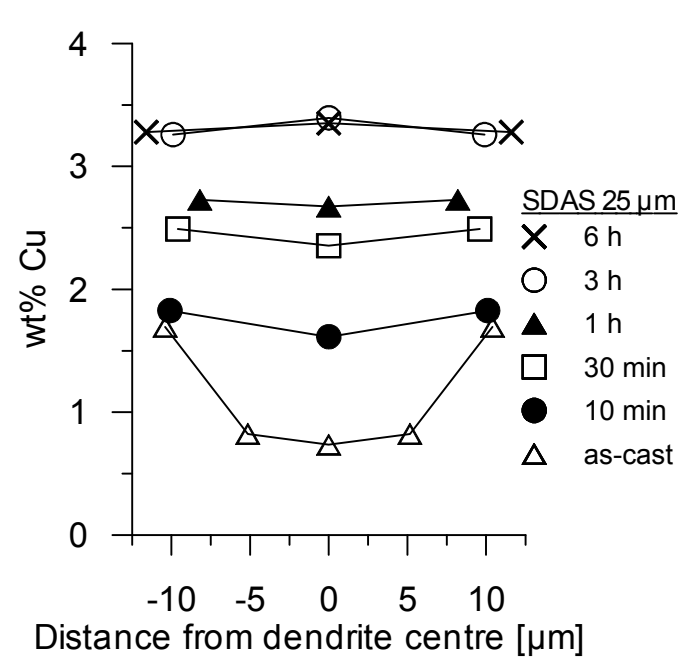

(b) 


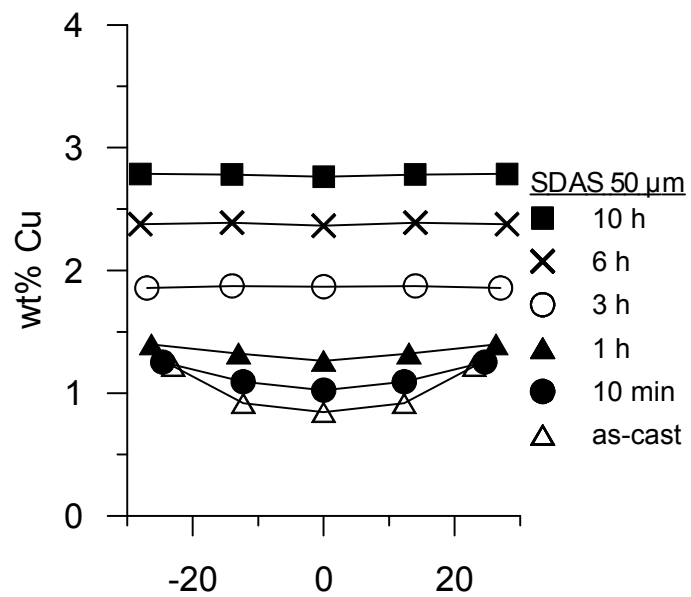

Distance from dendrite centre $[\mu \mathrm{m}]$

(c)

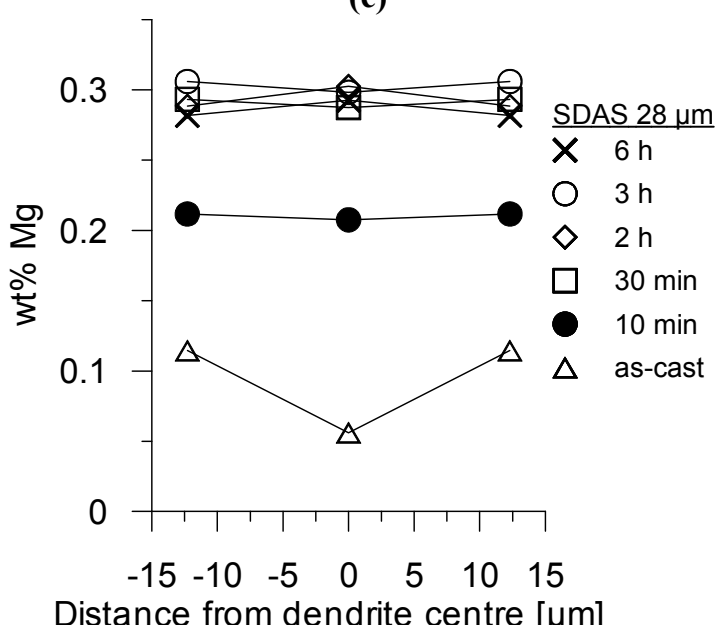

(e)

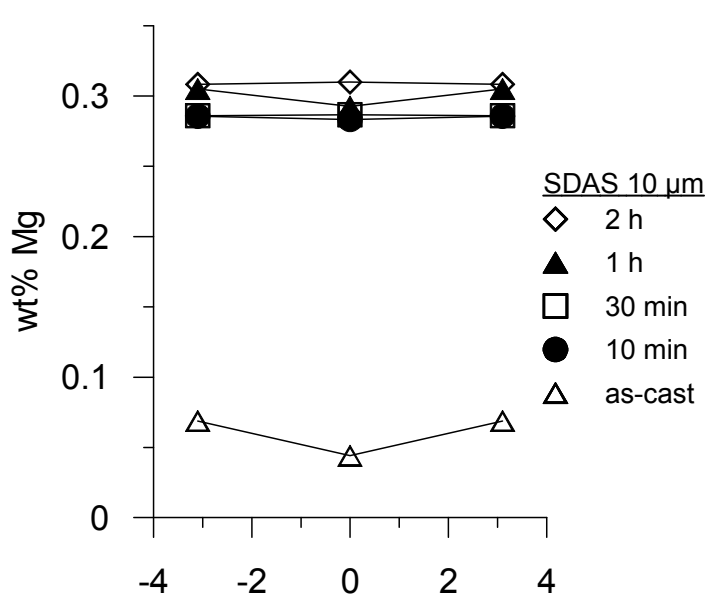

Distance from dendrite centre $[\mu \mathrm{m}]$

(d)

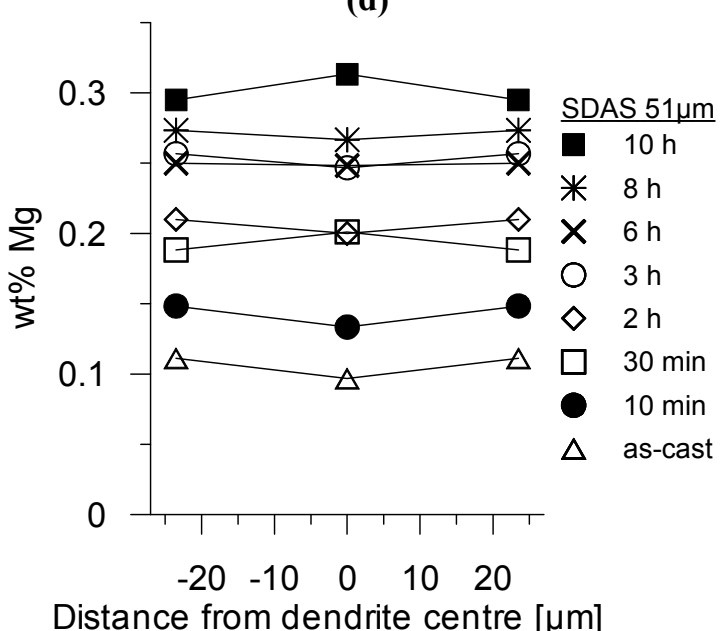

(f)

Figure 8 a-c) The increase in $\mathrm{Cu}$ concentration over dendrite arms for the Al-Si-Cu alloy solution treated at $495^{\circ} \mathrm{C}$ for SDAS of a) $10 \mu \mathrm{m}$, b) $25 \mu \mathrm{m}$ and c) $50 \mu \mathrm{m}$. d-f) $\mathrm{Mg}$ concentrations over dendrite arms for the Al-Si-Mg alloy solution treated at $530^{\circ} \mathrm{C}$ for SDAS of d) $10 \mu \mathrm{m}$, e) $28 \mu \mathrm{m}$ and f) $51 \mu \mathrm{m}$.

By introducing a dimensionless diffusion time, see eq. 8, it was investigated whether the differences in concentration increase for the different coarsenesses of the microstructure occur due to differences in diffusion distances, i.e. if the process is diffusion controlled. In eq. 8. $D$ is the diffusivity of $\mathrm{Mg}$ or $\mathrm{Cu}$ in the $\alpha$-Al phase at the solution treatment temperature and $r_{s}$ is the size of the diffusion field. A spherical diffusion geometry was used and its radius was calculated from the measured distance between $\mathrm{Mg} / \mathrm{Cu}$ rich phases, $L$, using eq. 9 .

$t_{d}=t_{S H T} D / r_{S}^{2}$

$r_{s}=L(3 / 4 \pi)^{1 / 3}$

The $\mathrm{Mg}$ concentration in the centre of dendrite arms for the Al-Si-Mg alloy after various solution treatment times is presented in Figure 9a. The distance between $\pi$-Fe phases was used to calculate the radius of the spherical diffusion field for the Al-Si-Mg alloy. Plotting the concentration of $\mathrm{Mg}$ in the centre of the dendrite arms versus the dimensionless diffusion time made the concentration curves for all three coarsenesses of the microstructure merge into one curve (Figure $9 \mathrm{~b}$ ), confirming that the process is diffusion controlled and that a spherical diffusion geometry can be used. The initial $\mathrm{Mg}$ concentration after solidification is not the same for all coarsenesses of the microstructure, which has an influence at short solution 
treatment times. This difference however levels out fast as homogenisation within the dendrite arms is a rapid process and the continued increase in $\mathrm{Mg}$ concentration comes from dissolution of distant $\pi$-Fe phases. The increase in $\mathrm{Mg}$ concentration during solution treatment for the $\mathrm{Al}-\mathrm{Si}-\mathrm{Cu}-\mathrm{Mg}$ alloy was also evaluated using the dimensionless diffusion time and the curves merged when SDAS was used to calculate the radius of the diffusion field, see Figure 9b. The low $\mathrm{Mg}$ concentration is due to the presence of the $\mathrm{Q}$ phase as already discussed.

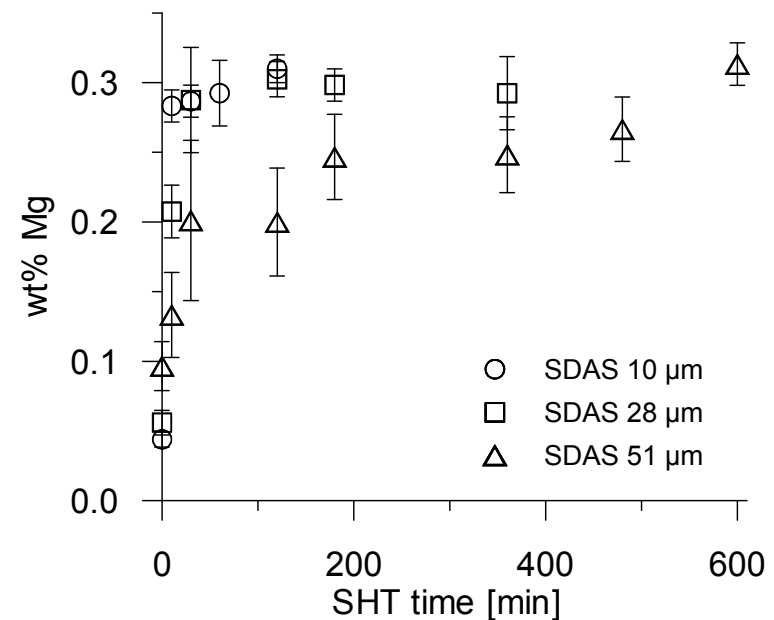

(a)

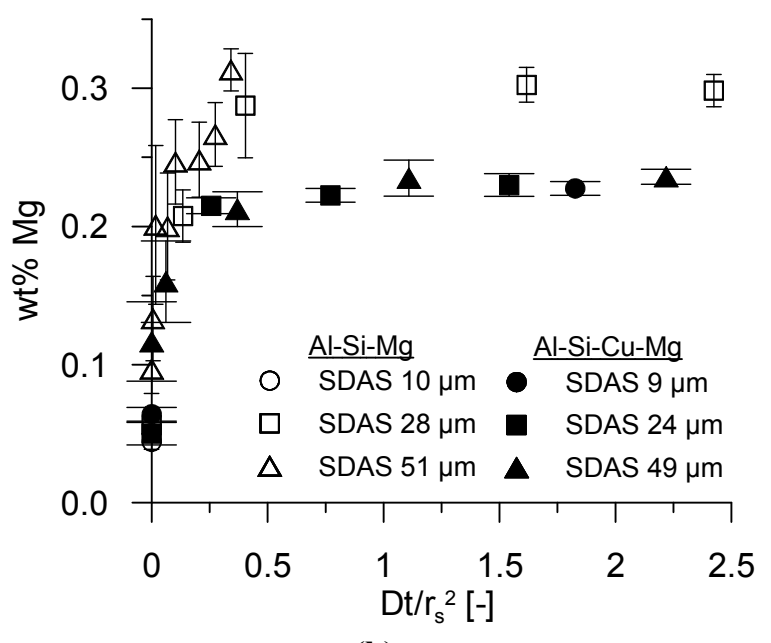

(b)

Figure 9 Increase in $\mathrm{Mg}$ concentration the centre of dendrite arms for the Al-Si-Mg alloy as a function of a) the solution treatment time and b) the dimensionless diffusion time, using the distance between $\pi$ Fe phases to calculate the radius of the diffusion field. Results for the Al-Si-Cu-Mg alloy is also included in b), where SDAS was used to calculate the radius of the diffusion field.

The increase in $\mathrm{Cu}$ concentration in the centre of dendrite arms for the Al-Si-Cu and Al-Si$\mathrm{Cu}-\mathrm{Mg}$ alloys after various solution treatment times is presented in Figure 10a. The $\mathrm{Cu}$ concentration curves for the different coarsenesses of the microstructure in Figure 10a merge into one curve when plotted versus the dimensionless diffusion time when the distance between $\mathrm{Al}_{2} \mathrm{Cu}$ phases is used to calculate the radius of the diffusion field, see Figure 10b. The $\mathrm{Cu}$ concentration increases a little faster for the $\mathrm{Al}-\mathrm{Si}-\mathrm{Cu}-\mathrm{Mg}$ alloy compared to the $\mathrm{Al}-\mathrm{Si}-\mathrm{Cu}$ alloy for the intermediate microstructure for solution treatment times up to $1 \mathrm{~h}$, as can be seen Figure 10a. The faster increase remains in Figure $10 \mathrm{~b}$ and the distance between $\mathrm{Al}_{2} \mathrm{Cu}$ phases is excluded as an explanation. A higher diffusivity of $\mathrm{Cu}$ in the $\alpha$-Al phase when $\mathrm{Mg}$ is present in solid solution can also be dismissed as an explanation for the faster increase in $\mathrm{Cu}$ in the $\mathrm{Al}-\mathrm{Si}-\mathrm{Cu}-\mathrm{Mg}$ alloy as it is only observed for short solution treatment times. Experimental variations in furnace temperature and heating rate could have caused the differences observed. The deviations observed are however almost covered by the standard deviation for the WDS measurements. 


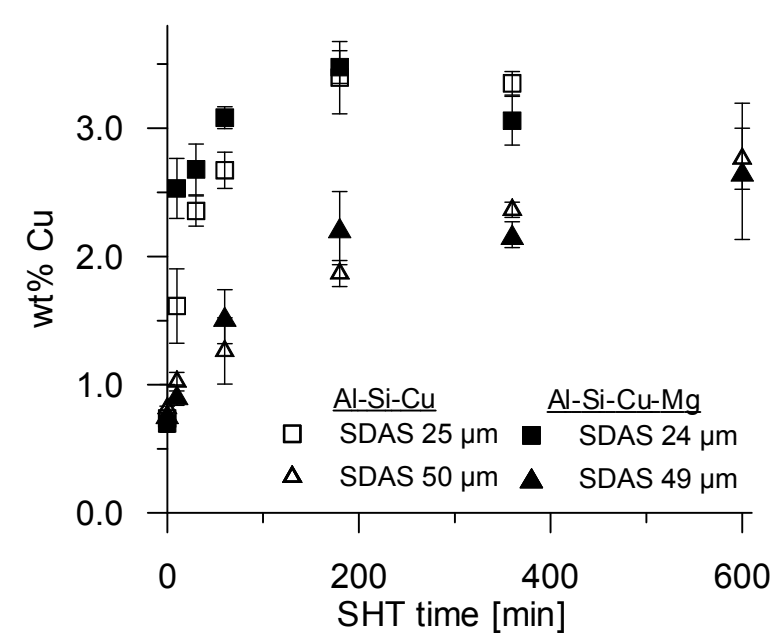

(a)

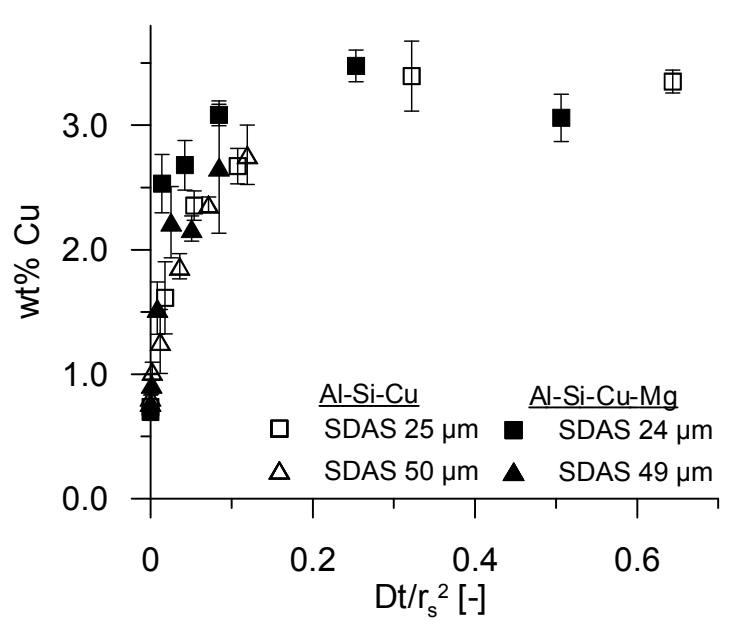

(b)

Figure 10 Concentration increase in the centre of dendrite arms for the Al-Si-Cu and $\mathrm{Al}-\mathrm{Si}-\mathrm{Cu}-\mathrm{Mg}$ alloys as a function of a) the solution treatment time and b) the dimensionless diffusion time, using the distance between $\mathrm{Al}_{2} \mathrm{Cu}$ phases to calculate the radius of the diffusion field. The results for the SDAS $10 \mu \mathrm{m}$ samples are excluded to improve the readability of the figures.

Phases that do not dissolve are undesirable, because firstly they may initiate and/or link fracture and secondly they bind alloying elements, which are therefore not available to increase the alloy strength by artificial ageing. Iron-containing phases are difficult to dissolve and are only present in low fractions in the investigated samples, due to the low $\mathrm{Fe}$ concentration of the alloys. A transformation from $\beta-\mathrm{Al}_{5} \mathrm{FeSi}$ plates into $\mathrm{Al}_{7} \mathrm{FeCu}_{2}$ plates was observed in the $\mathrm{Cu}$ containing alloys during solution treatment for the coarser microstructures (SDAS $25 \mu \mathrm{m}$ and $50 \mu \mathrm{m}$ ), which is in agreement with literature [48, 70]. An AlCuFeSi phase was observed for the finer microstructures, SDAS $10 \mu \mathrm{m}$ and $25 \mu \mathrm{m}$, which seems to be stable at $495^{\circ} \mathrm{C}$.

\subsection{INFLUENCE OF ARTIFICIAL AGEING ON THE YIELD STRENGTH, ELONGATION TO FRACTURE AND PLASTIC DEFORMATION (SUPPLEMENTS IV AND V)}

A heat treatment is normally applied to increase the yield strength of the alloy, but the plastic deformation behaviour will also be influenced.

\subsubsection{Yield strength}

The age hardening response of the Al-Si-Mg alloy is high and fast, compared to the Al-Si-Cu alloy which has a low and slow age hardening response, see Table 3. When both $\mathrm{Mg}$ and $\mathrm{Cu}$ are present the highest age hardening response is obtained. In $\mathrm{Al}-\mathrm{Si}-\mathrm{Cu}-\mathrm{Mg}$ alloys either the $\beta$ " phase or the Q" phase may form, or a combination of them $[35,36]$. The Q" phase is reported to shift the position of the peak yield strength towards longer ageing times [36, 39]. In this investigation the time to peak yield strength of the Al-Si-Cu-Mg alloy is longer than for the Al-Si-Mg alloy, indicating the presence of the Q" phase. The formation of the Q" phase may be a consequence of the use of natural ageing prior to artificial ageing [39]. A further difference between the $\mathrm{Al}-\mathrm{Si}-\mathrm{Mg}$ alloy and the Al-Si-Cu-Mg alloy is that the peak yield strength of the $\mathrm{Al}-\mathrm{Si}-\mathrm{Mg}$ alloy is less sensitive to the ageing temperature. It can be seen in Table 3 that the difference in age hardening response between the $\mathrm{Al}-\mathrm{Si}-\mathrm{Cu}-\mathrm{Mg}$ alloy and the $\mathrm{Al}-\mathrm{Si}-\mathrm{Mg}$ alloy is smaller for ageing at $210^{\circ} \mathrm{C}$ than at $170^{\circ} \mathrm{C}$. 
The coarseness of the microstructure did not have a large influence on the yield strength when the solution treatment time was chosen to be long enough to achieve complete dissolution and homogenisation. For the Al-Si-Mg alloy aged at $170^{\circ} \mathrm{C}$ the difference in peak yield strength between the coarsest and the finest microstructure was $7 \mathrm{MPa}$, see Figure 11a. The solution treatment time for the coarsest microstructures of the $\mathrm{Cu}$ containing alloys was not long enough, resulting in a lower concentration of $\mathrm{Cu}$ in solid solution and a lower yield strength after artificial ageing, see Figure $11 \mathrm{~b}$. The difference in peak yield strength for the SDAS $10 \mu \mathrm{m}$ and SDAS $25 \mu \mathrm{m}$ samples was $1-7 \mathrm{MPa}$ for ageing at $170^{\circ} \mathrm{C}$ or $210^{\circ} \mathrm{C}$.

Table 3 Age hardening response and peak properties for the three alloys.

\begin{tabular}{lcccccc}
\hline & \multicolumn{2}{c}{$\begin{array}{c}\text { Time to peak } \\
\mathrm{t}_{\text {peak }}[\mathrm{h}]\end{array}$} & $\begin{array}{c}\text { Age hardening response } \\
\Delta Y S ~[M P a]\end{array}$ & $\begin{array}{c}\text { Peak Properties for SDAS 25 } \mu \mathrm{m} \\
\text { Yield Strength [MPa] / Elongation (\%) }\end{array}$ \\
\hline Al-Si-Mg & $170^{\circ} \mathrm{C}$ & $210^{\circ} \mathrm{C}$ & $170^{\circ} \mathrm{C}$ & $210^{\circ} \mathrm{C}$ & $170^{\circ} \mathrm{C}$ & $210^{\circ} \mathrm{C}$ \\
Al-Si-Cu & 10 & 0.3 & 139 & 123 & $231 / 11$ & $213 / 12$ \\
Al-Si-Cu-Mg & $>170$ & 12 & 76 & 44 & $206 / 4$ & $175 / 6$ \\
\hline
\end{tabular}

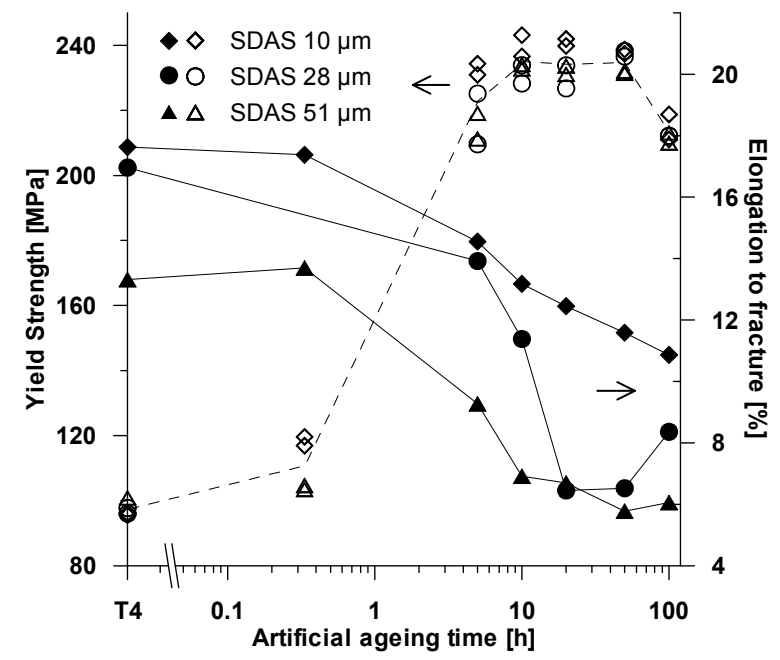

(a)

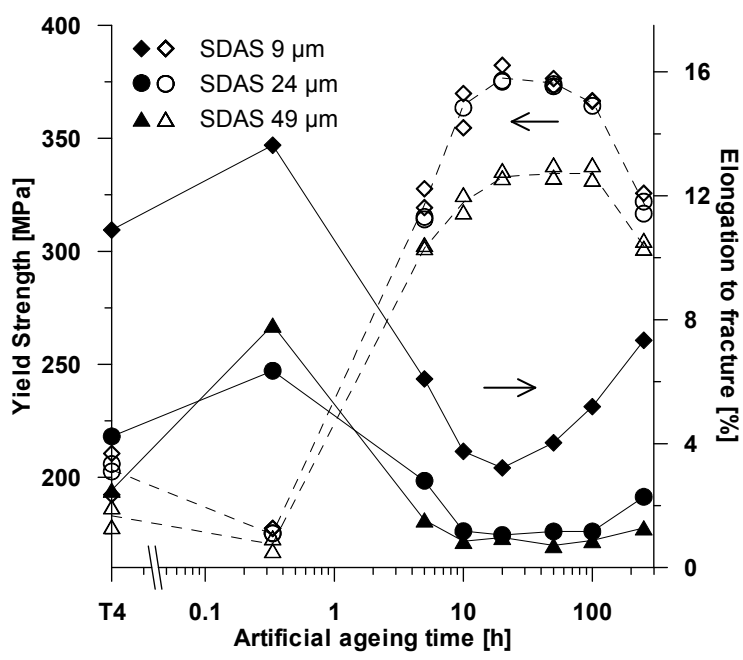

(b)

Figure 11 Evolution of yield strength and elongation to fracture during artificial ageing at $170^{\circ} \mathrm{C}$ for the a) Al-Si-Mg and b) Al-Si-Cu-Mg alloys. The lines are added to guide the eye. Note the different scales on the $y$-axis for the figure a) and $b$ ).

\subsubsection{Elongation to fracture}

An increase in yield strength generally leads to a decrease in ductility for a material that exhibits necking [71]. All samples of the Al-Si-Mg alloy having the finest microstructure reached necking, except the ones naturally aged or artificially aged $20 \mathrm{~min}$. at $170^{\circ} \mathrm{C}$. The elongation to fracture of the $\mathrm{Al}-\mathrm{Si}-\mathrm{Mg}$ alloy decreases when the yield strength increases during under ageing. The elongation to fracture however does not increase directly when the yield strength starts to decrease after the yield strength plateau, but remains low during initial overageing, see Figure $11 \mathrm{a}$. For longer overageing of $5 \mathrm{~h}$ at $210^{\circ} \mathrm{C}$, the elongation to fracture increases slightly. The values deviating from a continuous decrease in elongation to fracture for the intermediate microstructure seen in Figure 10a correspond to samples which fractured without reaching necking, which all the other samples did. The trend with the overaged condition giving a lower elongation to fracture for a certain yield strength compared to the underaged condition is clearer in the investigation made by Tiryakioglu et al. [72] who used 
longer ageing times. The formation of small Si particles in the matrix during initial overageing $[73,74]$ can be hypothesised to be the cause of the continued decrease in elongation to fracture during initial overageing.

Samples of the Al-Si-Cu-Mg alloy having the finest microstructure reach or are close to reaching necking, while samples of the coarser microstructures fracture before necking. The elongation to fracture for the finest microstructure of the $\mathrm{Al}-\mathrm{Si}-\mathrm{Cu}-\mathrm{Mg}$ alloy shows the expected behaviour and increases directly after the peak aged condition when the yield strength decreases, see Figure 11b. The two coarser microstructures of the Al-Si-Cu-Mg alloy have a low elongation to fracture, around $1 \%$, for ageing times between $10 \mathrm{~h}$ and $100 \mathrm{~h}$ at $170^{\circ} \mathrm{C}$. These ageing times correspond to the highest yield strength. The high yield strength in combination with larger brittle phases and defects in the coarser microstructures, compared to in the finest microstructure, is thought to cause the low elongation to fracture. An increase in elongation to fracture for the coarser microstructures is obtained when the yield strength has decreased significantly.

The Al-Si-Mg alloy in the underaged condition has a better combination of yield strength and elongation to fracture compared to the Al-Si-Cu-Mg alloy, see Figure 12. Al-Si-Mg alloys are therefore preferable to $\mathrm{Al}-\mathrm{Si}-\mathrm{Cu}-\mathrm{Mg}$ alloys, as long as the $\mathrm{Al}-\mathrm{Si}-\mathrm{Mg}$ alloys can reach the required strength.

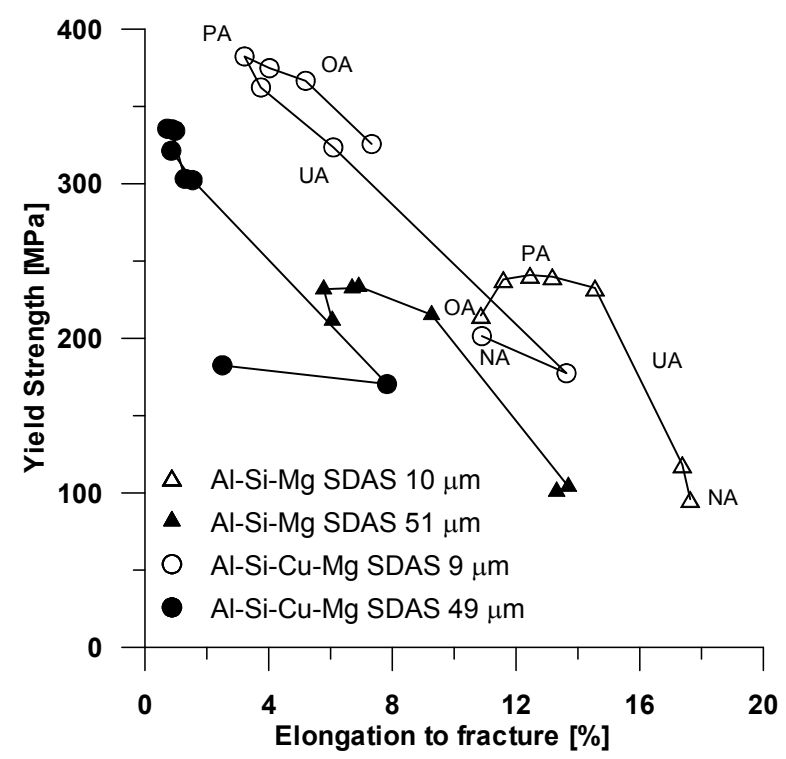

Figure 12 Correlation between yield strength and elongation to fracture for the Al-Si-Mg and Al-Si$\mathrm{Cu}-\mathrm{Mg}$ alloys. $\mathrm{NA}=$ natural aged, $\mathrm{UA}=$ underaged, $\mathrm{PA}=$ peak aged, $\mathrm{OA}=$ overaged.

\subsubsection{Plastic deformation behaviour}

\subsubsection{Hollomon and Ludwigson equations}

The strain hardening exponent, $n_{l}$, in the Hollomon equation (eq. 2) generally depends on the yield strength and on the mobility of the dislocations [75]. The correlation between $n_{t}$ and yield strength is shown in Figure 13 for data from the present investigation together with data from Alexopoulus et al. [76] for an Al-7Si-0.55Mg alloy and from Caceres et al. [77] for various $\mathrm{Al}-\mathrm{Si}-\mathrm{Cu}-\mathrm{Mg}$ alloys. One curve at low yield strength splits into two at higher yield strength, one for Al-Si-Mg alloys and $\mathrm{Al}-\mathrm{Si}-\mathrm{Cu}-\mathrm{Mg}$ alloys with low $\mathrm{Cu}$ and another for Al-Si$\mathrm{Cu}-\mathrm{Mg}$ alloys with high $\mathrm{Cu}$. The higher $n_{1}$ value for a certain yield strength for the Al-Si-Cu- 
$\mathrm{Mg}$ alloys compared to the $\mathrm{Al}-\mathrm{Si}-\mathrm{Mg}$ alloys is probably due to the higher fraction of obstacles to the moving dislocations in the Al-Si-Cu-Mg alloys.

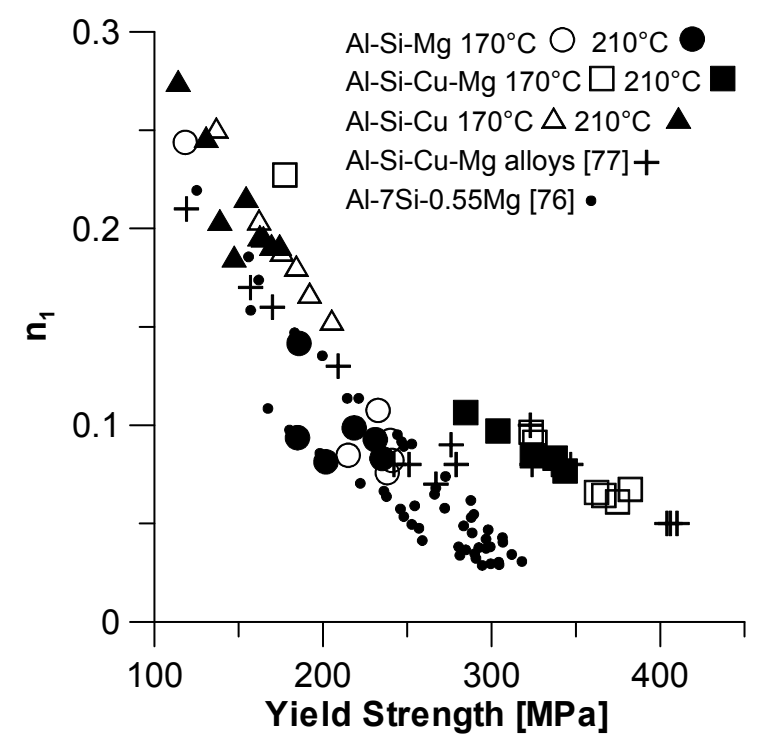

Figure 13 Relationship between the strain hardening exponent $n_{1}$ and yield strength.

\subsubsection{Kocks-Mecking strain hardening model}

The storage rate, $\theta_{0}$, and recovery rate, $K$, of dislocations in eq. 6 are correlated to the microstructure and can be used to obtain information regarding the coherency of the precipitates. Cheng et al. [78] proposed a correlation between the recovery rate and the coherency of the precipitates. A jump in recovery rate was proposed to be due to loss in coherency of the precipitates, which was confirmed with TEM studies by Poole et al. [79]. An increase in recovery rate at peak yield strength was observed for the alloys in the present investigation, but the increase was not as drastic as for wrought alloys. Furthermore, an increase in recovery rate at peak yield strength was observed for the Al-Si-Cu alloy, where semi- or non-coherent precipitates are thought to be present in the underaged condition [40], which questions the applicability of predicting the coherency from changes in recovery rate for Al-Si casting alloys.

The study of Simar et al. [80] shows better agreement with the present investigation. According to Simar et al. the storage rate has a minimum at the transition from shearable precipitates to a mixture of shearable and non-shearable precipitates and a maximum when all precipitates become non-shearable. These results raise the question whether the storage rate can be used to determine the coherency of the precipitates. This question can however not be answered by the present study as TEM studies of the coherency of the precipitates are needed to do so. The results of Simar et al. [80] are used to interpret the changes in storage rate and recovery rate for the alloys used in the present investigation.

The evolution of the storage rate during artificial ageing for the three alloys is shown in Figure 14. The storage rate decreases and the recovery rate increases with ageing time in the underaged condition for the $\mathrm{Al}-\mathrm{Si}-\mathrm{Mg}$ and $\mathrm{Al}-\mathrm{Si}-\mathrm{Cu}-\mathrm{Mg}$ alloys due to a decrease of atoms in solid solution. The storage rate has a minimum at the peak aged condition when the concentration of atoms in solid solution reaches its equilibrium value and the precipitates are shearable. The storage rate remains low at slight overageing for the Al-Si-Mg alloy (Figure $14 \mathrm{a})$, indicating that the precipitates remain coherent, to increase at longer overageing. The storage rate of the Al-Si-Cu-Mg alloy on the other hand seems to increase directly at 
overageing (Figure 14b), indicating that a mixture of coherent and non-coherent precipitates form, where the non-coherent precipitates are looped by dislocations contributing to the storage rate of dislocations. The magnitude of the storage rate is much larger for the Al-Si-Cu$\mathrm{Mg}$ alloy compared to the Al-Si-Mg alloy due to the higher solute concentration in the Al-Si$\mathrm{Cu}-\mathrm{Mg}$ alloy giving a larger density of obstacles to dislocation motion. The Al-Si-Cu alloy shows a continuous increase in storage rate with ageing time at the underaged condition (Figure 14c), indicating a presence of a mixture of coherent and non-coherent precipitates. The storage rate decreases on overageing, indicating that all precipitates are non-coherent. The number of precipitates decreases on overageing, thereby decreasing the probability for interaction between precipitates and dislocations and leading to a decrease in storage rate of dislocations.

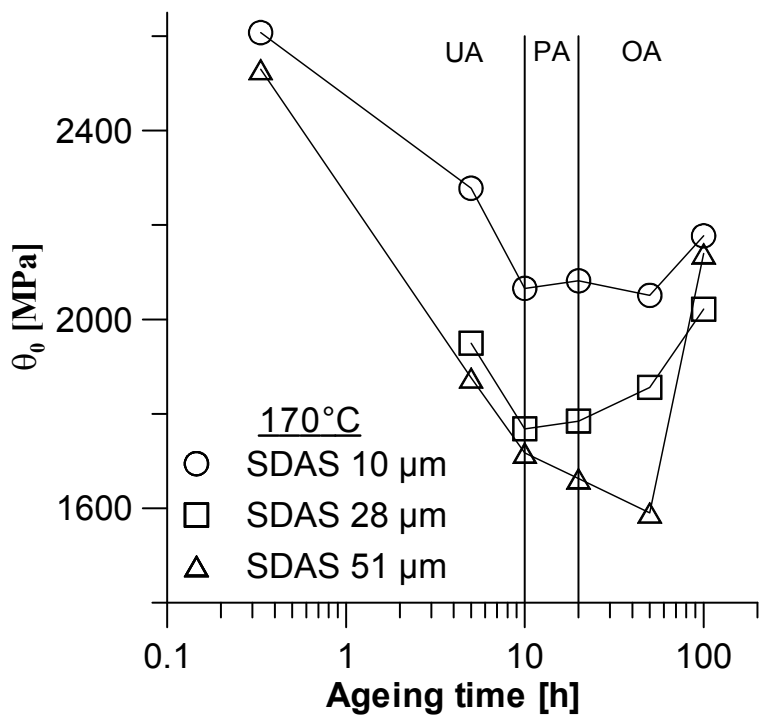

(a)

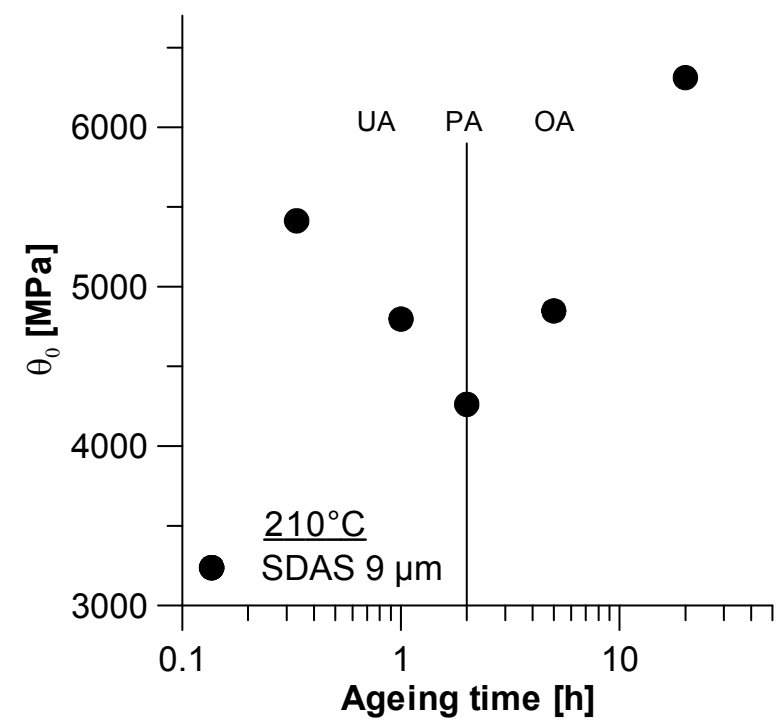

(b)

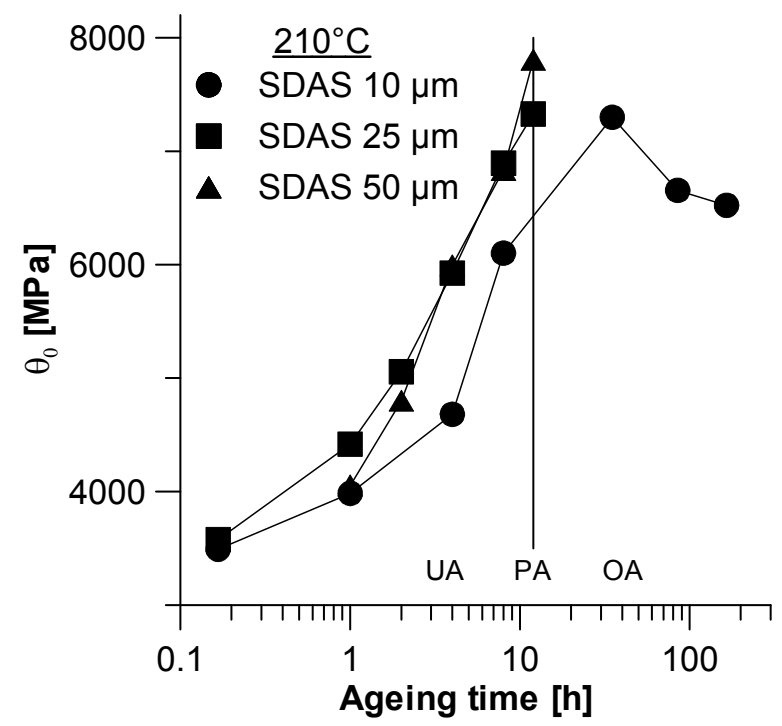

(c)

Figure 14 Evolution of storage rate of dislocations with ageing time for the a) Al-Si-Mg, b) Al-Si-Cu$\mathrm{Mg}$ and c) Al-Si-Cu alloys. $\mathrm{UA}=$ underaged, $\mathrm{PA}=$ peak aged, $\mathrm{OA}=$ overaged.

The coarseness of the microstructure, $S D A S$, influences the strain hardening rate, being higher with a smaller $S D A S$. The recovery rate is not influenced by $S D A S$. The storage rate increases with decreasing SDAS for the Al-Si-Mg alloy (Figure 14a) as a consequence of the shorter 
distance for dislocations to move to reach the eutectic where they are blocked [58, 81]. The storage rate of the Al-Si-Cu alloy (Figure 14c) shows the opposite dependence on SDAS compared to the Al-Si-Mg alloy. This contradictory result for the Al-Si-Cu alloy is probably due to the presence of defects influencing the shape of the plastic part of the stress-strain curves [82] and the region which can be used to derive $K$ and $\theta_{0}$.

\subsection{MODELLING OF THE HEAT TREATMENT PROCESS (SUPPLEMENTS II, III, V AND VI)}

To be able to model the tensile properties after artificial ageing the evolution of the microstructure starting from solidification has to be modelled.

\subsubsection{Modelling of the microstructure}

\subsubsection{Solidification and solution treatment}

Scheil segregation was used to model the concentration profiles in the as-cast condition. It would have been necessary to include back diffusion to calculate the as-cast yield strength. Scheil segregation however gives an adequate initial condition for modelling of the solution treatment. The geometry consists of a number of $\mathrm{Mg}$ or $\mathrm{Cu}$ rich particles with an interparticle distance, $L$, see Figure 15a. The particles are assumed to be spherical and are assigned their stoichiometric composition. The particles of interest are $\mathrm{Al}_{2} \mathrm{Cu}$ particles for the $\mathrm{Cu}$ containing alloys and $\pi$-Fe particles for the Al-Si-Mg alloy. The radius of the spherical diffusion field, $r_{s}$, is calculated from the measure interparticle distance, using equation 9. A mesh covering the matrix i.e. having its left boundary at the particle-matrix interface and its right boundary at the end of the diffusion field, $r$, is introduced, see Figure 15b. Local equilibrium is assumed at the particle-matrix interface and the concentration, $C_{i n t}$, is obtained from ThermoCalc [9]. Due to symmetry a zero flux boundary condition is used at $r_{s}$. The geometry of the model with associated concentrations is summarised in Figure 15c.

The calculation routine for dissolution and homogenisation is as follows:

1. Diffusion in the matrix $\left[r_{\text {part }}, r_{s}\right]$ is calculated using Ficks $2^{\text {nd }}$ law and the finite difference method for a time step $\Delta t$.

2. The total concentration in the matrix is calculated. A new particle radius is calculated using mass balance.

3. A new mesh is generated between the new radius $r_{\text {part }}$ and $r_{s}$, and the concentrations are transferred to the new mesh.

The calculations (step 1 to 3 ) continue until the particle has dissolved. The boundary condition at the particle-matrix interface is then relaxed and homogenisation in the matrix is calculated (i.e. only step 1) until equilibrium is reached. 


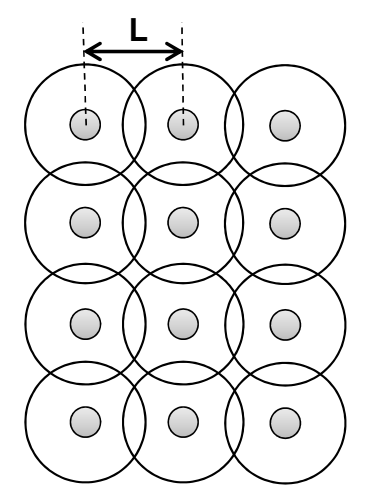

(a)

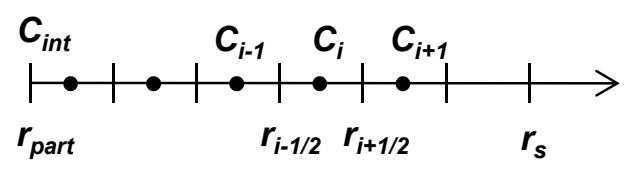

(b)

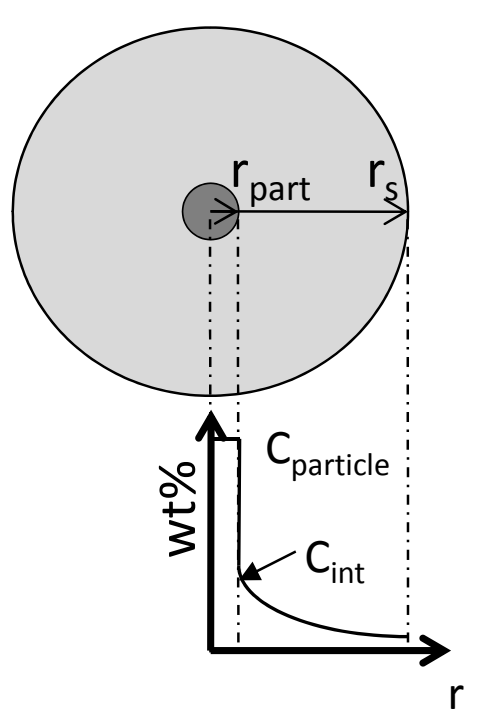

(c)

Figure 15 Geometry of the model.

The model gave a good fit for solution treatment of the Al-Si-Mg alloy, see Figure 16a. The equilibrium concentration predicted by the model, $0.34 \mathrm{wt} \% \mathrm{Mg}$, was however slightly higher than the measured concentration, $0.31 \mathrm{wt} \% \mathrm{Mg}$. The discrepancy could be due to lack of the temperature control of the furnace, or due to the uncertainty in the determination of the $\mathrm{Mg}$ concentration of the alloy using OES or the Mg concentration of the matrix using WDS. To be able to model the increase of $\mathrm{Mg}$ in the $\mathrm{Al}-\mathrm{Si}-\mathrm{Cu}-\mathrm{Mg}$ alloy the solubility of $\mathrm{Mg}$ in the $\alpha-\mathrm{Al}$ phase at $495^{\circ} \mathrm{C}$ must be known. ThermoCalc predicts a solubility of $0.32 \mathrm{wt} \% \mathrm{Mg}$ in the $\alpha$ $\mathrm{Al}$ phase at $495^{\circ} \mathrm{C}$ [9], which is much higher than the measured concentration. Changing the solubility limit at $495^{\circ} \mathrm{C}$ to $0.25 \mathrm{wt} \% \mathrm{Mg}$ gave a good fit between measured and calculated $\mathrm{Mg}$ concentrations for the Al-Si-Cu-Mg alloy, see Figure 16a.

The model was initially not able to predict the concentration increase of $\mathrm{Cu}$ during solution treatment. A higher diffusivity of $\mathrm{Cu}$ in the Al-Si eutectic compared to in the primary $\alpha$-Al phase has been reported by Zhang et al. [83], which is a possible reason for the discrepancy. A much higher diffusivity in the $\mathrm{Al}-\mathrm{Si}$ eutectic means that diffusion in the primary $\alpha-\mathrm{Al}$ phase will be rate controlling. The measured distance between the $\mathrm{Al}_{2} \mathrm{Cu}$ phases was therefore reduced only to include the primary $\alpha$-Al phase. The $\mathrm{Al}-\mathrm{Si}-\mathrm{Cu}$ and $\mathrm{Al}-\mathrm{Si}-\mathrm{Cu}-\mathrm{Mg}$ alloys contain $7.8 \mathrm{wt} \% \mathrm{Si}$ and $8.5 \mathrm{wt} \% \mathrm{Si}$ respectively, which corresponds to microstructures having about 40 and 35 volume \% respectively of primary $\alpha-\mathrm{Al}$ phase. The agreement between model and experimental data is very good when a reduced diffusion distance is used, as can be seen for the Al-Si-Cu alloy in Figure 16b. 


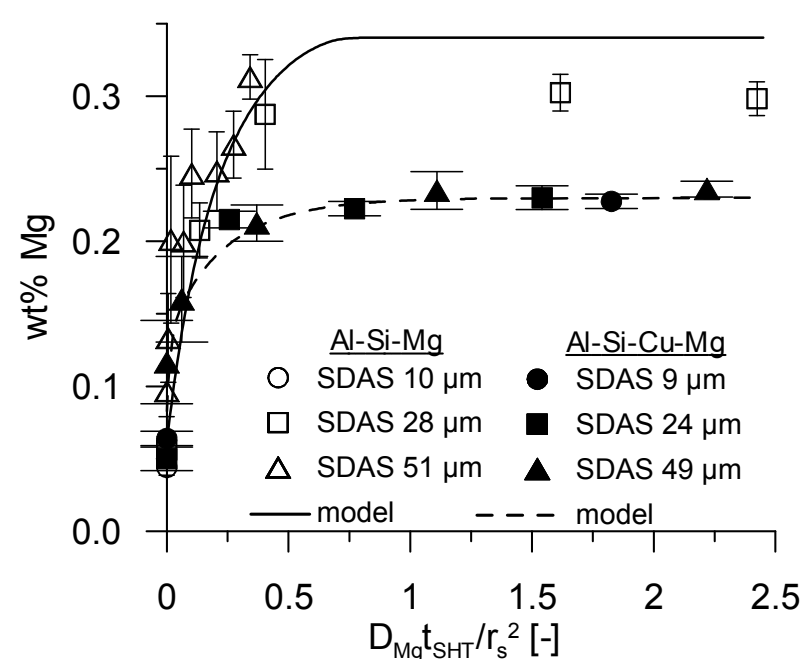

(a)

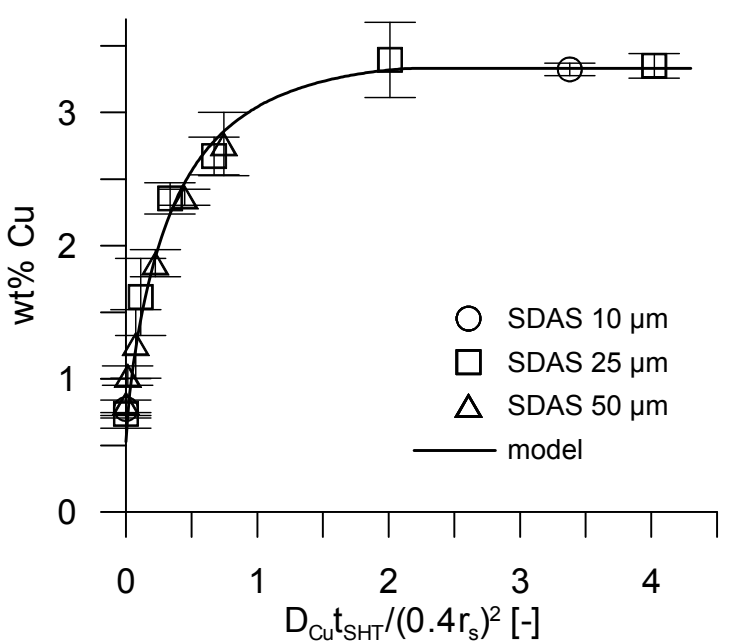

(b)

Figure 16 Comparison between model and the experiments for the a) Al-Si-Mg and Al-Si-Cu-Mg and b) Al-Si-Cu alloys.

\subsubsection{Artificial ageing}

The microstructure evolution during artificial ageing was only modelled for Al-Si-Mg alloys, as more work is needed to understand the appearance of the ageing curves for Al-Si-Cu-Mg alloys. From the solution treatment model the average concentration of $\mathrm{Mg}$ dissolved in the matrix is used as input to the artificial ageing model. Spherical precipitates are assumed to form by instantaneous nucleation and the supersaturation of vacancies is assumed to be lost at the nucleation event. One precipitate having a constant composition is used for the whole ageing sequence. The $\beta$ " phase having a composition of $\mathrm{Mg}_{5} \mathrm{Si}_{6}[84]$ is chosen as it is present in the peak aged condition and gives the largest strength contribution. The $\beta$ " phase is also present in the under- and overaged condition, but in combination with other precipitates [33, $85,86]$. The number density of precipitates formed is an important parameter as it determines the time to reach peak yield strength. Particle dimensions for the peak aged condition reported in the literature $[74,87]$ were used to estimate the number of precipitates under the assumption that the concentration of alloying elements in the matrix reaches its equilibrium value at the ageing temperature. The exact number density is obtained by calibration, as will be discussed in section 3.4.2. The precipitates grow by diffusion of $\mathrm{Mg}$ from the surrounding supersaturated matrix. The growth is calculated using the same approach as for dissolution as discussed in the previous section. When the supersaturation of the matrix is lost the continued growth of the precipitates is calculated using the LSW coarsening law.

\subsubsection{Modelling of strength}

\subsubsection{Modelling of the yield strength of the Al-Si-Mg alloy}

As discussed in Section 1.5.2 the total yield strength is composed of contributions from atoms in solid solution, shearable and non-shearable precipitates as well as contributions which do not change during artificial ageing. The total yield strength is given by eq. $1\left(\sigma_{t o t}=\sigma_{i}+\sigma_{s s}+\right.$ $\left.\left(\sigma_{d i s}^{q}+\sigma_{p p t}^{q}\right)^{1 / q}\right)$. The mathematical expressions used for the different contributions $\left(\sigma_{i}, \sigma_{s s}\right.$, $\left.\sigma_{d i s}, \sigma_{p p t}\right)$ are presented in the following text. The microstructure parameters from the microstructure model which are used in the strength equations are: i) the concentration of $\mathrm{Mg}$ and $S i$ in the $\alpha$-Al matrix, $C_{M}^{M g}$ and $C_{M}^{S i}$, ii) the radius of the precipitates, $r_{p p t}$, and iii) the fraction of the precipitates, $f_{p p t}$. 
The intrinsic strength, $\sigma_{i}$, was calculated from the measured yield strength of as-quenched binary $\mathrm{Al}-\mathrm{Si}$ samples by subtracting the strength contribution from $\mathrm{Si}$ atoms in solid solution and dislocations.

A linear equation was used for the solid solution hardening, $\sigma_{s s}$, as it gave the best fit to the data sets found in the literature, see eq. 10.

$\sigma_{S S}=17 C_{M}^{M g}+11 C_{M}^{S i}$

When modelling the yield strength the dislocations present are the ones formed during quenching from the solution treatment temperature due to the difference in thermal expansion between the $\alpha-\mathrm{Al}$ phase and the Si particles. Equations for composites can be used to estimate the dislocation density. The strength contribution from dislocations, $\sigma_{d i s}$, is given by eq. 5 .

A strain field appears at coherent precipitates due to the difference in lattice constants between the matrix and the precipitate. Dislocations interact with the strain field impeding their motion. Coherency strengthening is used to model the strength contribution from shearable precipitates, in accordance with eq. $11[5,53]$, where $k_{c o b}$ is a constant between three and four and $\varepsilon$ the constrained misfit parameter. When the precipitates are looped by dislocations their strength contribution is given by the Orowan equation (eq. 12) [5, 88], where $v_{\alpha}$ is Poisson's ratio of the $\alpha-\mathrm{Al}$ matrix.

$$
\begin{aligned}
& \sigma_{p p t}^{\text {coh }}=k_{c o h}^{3 / 2} M G_{\alpha} \varepsilon^{3 / 2} \sqrt{\frac{3 f_{p p t} r_{p p t}}{2 \pi b}} \\
& \sigma_{p p t}^{\text {Orowan }}=\frac{0.81 G_{\alpha} b}{2 \pi \sqrt{1-\vartheta_{\alpha}}} \frac{\ln \left(\pi r_{p p t} / 2 b\right)}{\left(\sqrt{2 \pi / 3 f_{p p t}}-\pi / 2\right) r_{p p t}}
\end{aligned}
$$

The present microstructure model calculates an average value for the radius of the precipitates. In reality the precipitates have a size distribution, which will influence the strength by a reduction related to the width of the size distribution. Wang et al. [39] has measured the radius of the precipitates during ageing and found that the standard deviation was about 0.2 times the average radius. This relation together with the strength relation for a size distribution derived by Deschamps et al. [51] was used to include a size distribution in the expression for the precipitates strength, $\sigma_{p p t}$.

When all strength contributions are identified the final step is the choice of a superposition law. No clear direction is given in the literature about how to treat the situation for yield strength. Fortunately the choice is not critical for the present model as calibration is used to determine $k_{c o b}$ and the superposition law will only have a small influence for short ageing times. A Pythagorean superposition law was used in the present model, i.e. $q=2$ in eq. 1 .

Calibration of the model was necessary as all parameter values are not known exactly, but only the range they should be within. These parameters were determined through calibration against the measured ageing curves for $170^{\circ} \mathrm{C}$ and $210^{\circ} \mathrm{C}$ shown in Figure $17 \mathrm{a}$. The parameters were varied within their specified limits to find the combination giving the smallest mean square error. The parameters obtained through calibration are the radius of the precipitates at peak yield strength, the prefactor for coherency strengthening, $k_{c o b}$, the lattice misfit and the precipitate-matrix interfacial energy. The result of the calibration is given in Figure $17 \mathrm{a}$ and an example of validation of the model using data from the literature is given in Figure 17b. The model predicts the strength for the overaged condition well, while the underaged condition is less well described. The deviation is thought to be due to a too simple model for the microstructure in the underaged condition, but the strength equations used 
should also be reviewed. The influence of a size distribution of the precipitates on the total strength is shown in Figure 17a. Included in the figure is also the total strength for shearable and non-shearable precipitates.

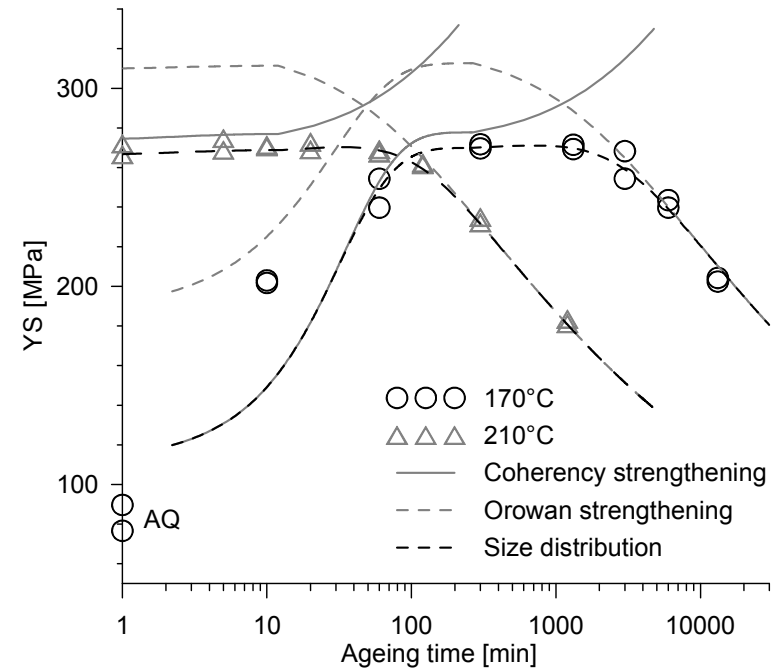

(a)

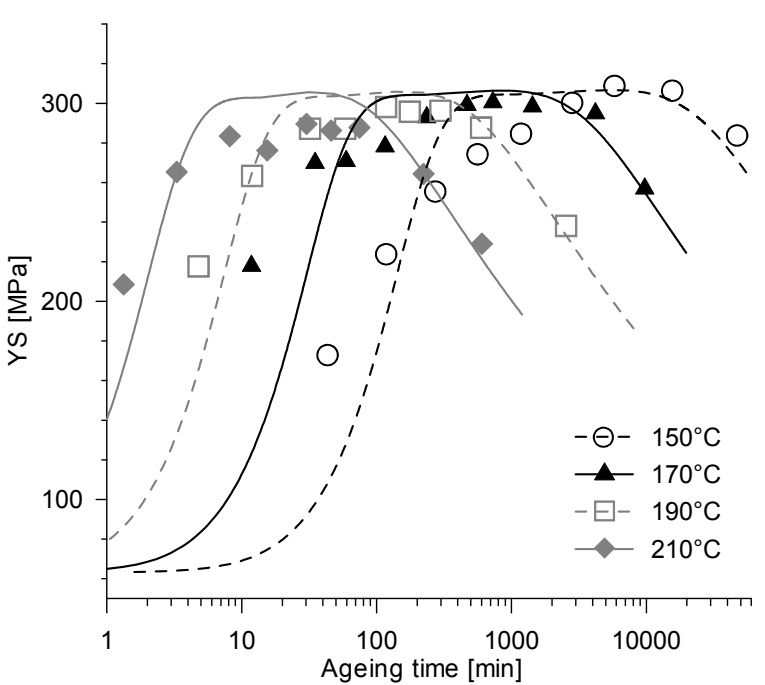

(b)

Figure 17 a) Result of the calibration. b) Showing the agreement between modelled and measured data from the literature for an Al-7Si-0.6Mg alloy aged at four different temperatures [89].

\subsubsection{Modelling of the plastic deformation}

For the Al-Si-Cu alloy there are indications, in the literature [40] and from the analysis in Section 3.3.3.2, that a mixture of coherent and non-coherent precipitates are already present in the underaged condition. When non-coherent precipitates are present the KM model for pure metals needs to be modified in accordance with the discussion in Section 1.5.2. A Pythagorean superposition law (i.e. $q=2$ in eq. 1 ) is used and $k_{1}$ in eq. 7 is set to zero, thus assuming that moving dislocations are more likely to interact with precipitates than with other dislocations. Under these conditions eq. 13 is derived, where $\beta=\alpha^{2} M^{3} G^{2} b^{2} k_{D} / 2$.

$\frac{d \sigma_{d i s}}{d \varepsilon_{p}}=\frac{\beta}{\sigma_{d i s}}-K \sigma_{d i s}$

The KM equations can be used to calculate the strength contribution from dislocations, $\sigma_{d i s}$, by integration of equations 6 and 13 yielding eq. 14 and 15, which together with eq. 1 gives the relation between true stress and true plastic strain. In eq. $14-15 \sigma_{d i s}^{i}$ and $\varepsilon_{p}^{i}$ is an initial dislocation strength at an initial plastic strain.

$\sigma_{d i s}=\frac{\theta_{0}}{K}-\left(\frac{\theta_{0}}{K}-\sigma_{d i s}^{i}\right) \exp \left(-K\left(\varepsilon_{p}-\varepsilon_{p}^{i}\right)\right)$

$\sigma_{\text {dis }}^{2}=\frac{\beta}{K}-\left(\frac{\beta}{K}-{\sigma_{\text {dis }}^{i}}^{2}\right) \exp \left(-2 K\left(\varepsilon_{p}-\varepsilon_{p}^{i}\right)\right)$

Samples having a large content of a) atoms in solid solution, b) coherent precipitates and c) non-coherent precipitates, demonstrates three different plastic deformation behaviours. The ability of the Hollomon, Ludwigson and KM equations to describe these plastic stress-strain curves is shown in Figure 18. 


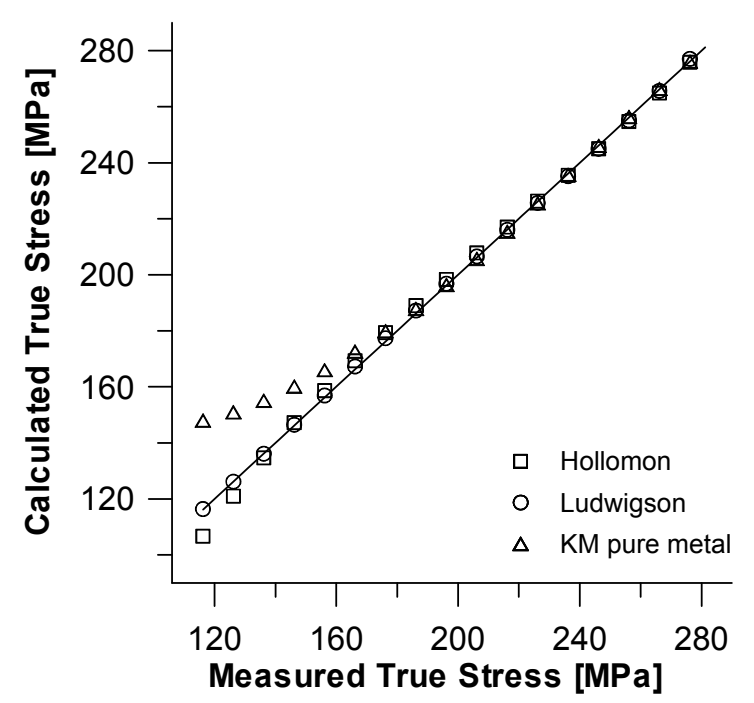

(a)

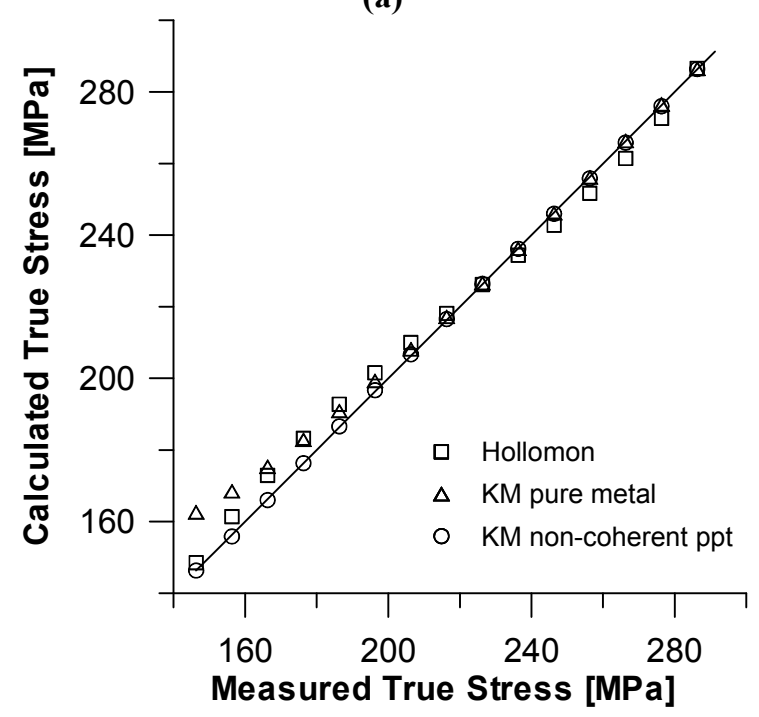

(c)

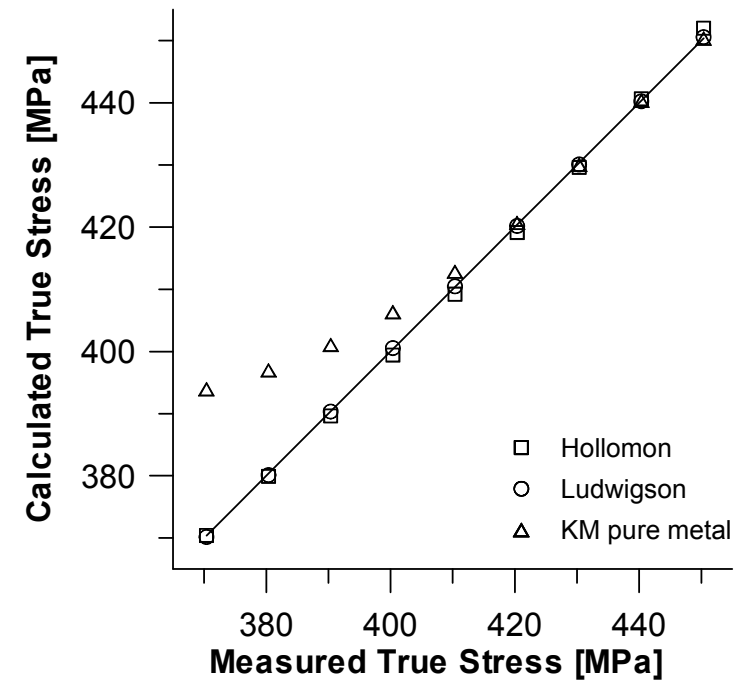

(b)

Figure 18 Showing the accuracy of the fit for samples containing large amounts of a) solid solution $\left(\mathrm{Al}-\mathrm{Si}-\mathrm{Mg} 20 \mathrm{~min} 170^{\circ} \mathrm{C}\right.$ SDAS $\left.10 \mu \mathrm{m}\right)$ b) coherent precipitates (Al-Si-Cu-Mg $10 \mathrm{~h} 170^{\circ} \mathrm{C}$ SDAS $\left.9 \mu \mathrm{m}\right)$ and c) non-coherent precipitates (Al-Si-Cu 85 h $210^{\circ} \mathrm{C}$ SDAS $\left.10 \mu \mathrm{m}\right)$.

The Hollomon equation describes the plastic deformation well when coherent precipitates are present, see Figure 18b. The Ludwigson equation is needed when a supersaturated solid solution is present which influences the plastic deformation behaviour at small strains, see Figure 18a. Neither the Hollomon nor the Ludwigson equation can describe the shape of the plastic part of the stress-strain curves of the Al-Si-Cu alloy accurately. The complicated shape is suggested to be due to the presence of non-coherent precipitates. The result of the Hollomon equation is shown in Figure 18c, but the Ludwigson equation gives similar results. The recommendation is to use the Hollomon equation, as the Ludwigson equation is more complicated and does not improve the fit.

The KM model for pure metals gives a good fit for the last part of the curve for all alloys and heat treatment conditions, while the deviations are larger for small strains. The large deviation at small strains is however expected as the equations are valid for a homogenous strain distribution. The KM model for non-coherent precipitates gives an excellent fit to the measured curve for the Al-Si-Cu alloy, see Figure 18c. The KM model for non-coherent precipitates improves the fit for small strains compared to KM model for pure metals. It was 
noticed that the KM model for non-coherent precipitates can improve the fit also for the Al$\mathrm{Si}-\mathrm{Mg}$ and $\mathrm{Al}-\mathrm{Si}-\mathrm{Cu}-\mathrm{Mg}$ alloys, compared to the KM model for pure metals, but the fit is far from as good as for the $\mathrm{Al}-\mathrm{Si}-\mathrm{Cu}$ alloy. This indicates that the use of a linear superposition law and $k_{D}=0$ in eq. 7 for shearable precipitates should be reconsidered. 
SUMMARY OF RESULTS AND DISCUSSION 


\section{CONCLUDING REMARKS AND FUTURE WORK}

\subsection{CONCLUDING REMARKS}

The aim of creating a model for the yield strength of heat treated Al-Si alloys was reached for $\mathrm{Al}-\mathrm{Si}-\mathrm{Mg}$ alloys. The development of a model for the plastic part of the stress-strain curve has been initiated with a comparison of different models available in the literature. During the work towards modelling of the tensile properties of heat treated alloys new knowledge has been gained concerning the microstructure formation during solidification and its evolution during heat treatment, and the relation between microstructure and strength.

Solidification (Supplements I, II \& III)

$>$ The $\pi$-Fe phase was the main Mg containing phase formed in the Al-Si-Mg alloy. The fraction of the $\pi$-Fe phase was observed to increase, while the fraction of the $\beta$-Fe phase decreased with increasing solidification rate. $\mathrm{The}_{2} \mathrm{Al} \mathrm{Cu}$ phase was the main $\mathrm{Cu}$ containing phase in the Al-Si-Cu and Al-Si-Cu-Mg alloys. The $\mathrm{Q}$ phase formed in addition to the $\mathrm{Al}_{2} \mathrm{Cu}$ phase in the $\mathrm{Al}-\mathrm{Si}-\mathrm{Cu}-\mathrm{Mg}$ alloy. These observations are in agreement with the literature.

$>$ The distance between the $\mathrm{Mg} / \mathrm{Cu}$ rich phases increases faster than the SDAS increases with decreasing solidification rate. There are however indications that these observations may be limited to directional solidified samples, while the distribution of $\mathrm{Mg} / \mathrm{Cu}$ rich phases is more uniform for equiaxed solidified samples.

$>$ The segregation profile of $\mathrm{Mg}$ is influenced by back diffusion giving a higher $\mathrm{Mg}$ concentration in the centre of the dendrite arms for a slow solidification as diffusion is allowed to take place over a longer time. The segregation profiles for $\mathrm{Cu}$ are only weakly dependent on the solidification rate due to the slower diffusivity of $\mathrm{Cu}$ compared to $\mathrm{Mg}$ in the $\alpha-\mathrm{Al}$ phase.

\section{Solution treatment (Supplements I, II \& III)}

$>$ ThermoCalc can predict the solubility limit of Si at the solution treatment temperature well. Furthermore the stability of the phases in the Al-Si-Mg and Al-Si-Cu alloy is correctly predicted. For the $\mathrm{Al}-\mathrm{Si}-\mathrm{Cu}-\mathrm{Mg}$ alloy a too high solubility of $\mathrm{Mg}$ in the $\alpha-\mathrm{Al}$ phase at $495^{\circ} \mathrm{C}$ was predicted.

$>$ The time needed for dissolution and homogenisation is strongly dependent on the coarseness of the microstructure. As an example; $10-30 \mathrm{~min}$. at $495^{\circ} \mathrm{C}$ was sufficient to achieve complete dissolution and homogenisation for the finest microstructure of the $\mathrm{Cu}$-containing alloys, while more than $10 \mathrm{~h}$ was needed for the coarsest microstructure. 
$>$ The solution treatment process was shown to be diffusion controlled using a dimensionless diffusion time. The diffusivity of the alloying elements was not influenced by the presence of other alloying elements.

Artificial ageing (Supplements I, IV \& V)

There is a good agreement between different literature investigations regarding the yield strength of artificially aged Al-Si-Mg alloys. The measurements conducted in this work are also in good agreement with data sets from the literature. The situation is more complex for $\mathrm{Al}-\mathrm{Si}-\mathrm{Cu}-\mathrm{Mg}$ alloys as different precipitates form and there is a large scatter in the data found in the literature. Different results are obtained from what seem to be identical investigations. Measurements made in this work does not contribute to any clarification regarding this issue, but the results are in line with data from the literature and existing ideas for wrought alloys.

The KM strain hardening theory provides information regarding the coherency of the precipitates. From these studies it is indicated that the precipitates of the Al-Si-Mg alloy remain coherent on initial overageing, while some of the precipitates of the $\mathrm{Al}-\mathrm{Si}-\mathrm{Cu}$ $\mathrm{Mg}$ alloy lose coherency directly on overageing. For the Al-Si-Cu alloy there is already a mixture of coherent and non-coherent precipitates on underageing, changing into only non-coherent precipitates on overageing.

$>$ The elongation to fracture increases directly after the peak yield strength for the Al-Si$\mathrm{Cu}-\mathrm{Mg}$ alloy having the finest microstructure, while it continue to decrease on initial overageing for the Al-Si-Mg alloy. This is suggested to be due to formation of Si precipitates in the matrix. The coarser microstructures of the $\mathrm{Al}-\mathrm{Si}-\mathrm{Cu}-\mathrm{Mg}$ alloy showed a low elongation to fracture around 1\% for ageing times corresponding to a high yield strength. The high yield strength in combination with larger defects in the coarser microstructures is thought to be the reason for the low elongation to fracture.

Modelling (Supplements II, III, V and VI)

A solution treatment model that can handle the three alloys investigated has been developed. The solubility limit of $\mathrm{Mg}$ at the solution treatment temperature was adjusted for the $\mathrm{Al}-\mathrm{Si}-\mathrm{Cu}-\mathrm{Mg}$ alloy due to the presence of the stable $\mathrm{Q}$ phase. A reduced diffusion distance between the $\mathrm{Al}_{2} \mathrm{Cu}$ phases only including the primary $\alpha-\mathrm{Al}$ phase was introduced due to a reported high diffusivity of $\mathrm{Cu}$ in the Al-Si eutectic.

A model for the yield strength of heat treated Al-Si-Mg casting alloys has been developed which can handle $\mathrm{Mg}$ concentrations in the range $0.2 \mathrm{wt} \%$ to $0.6 \mathrm{wt} \%$ and temperatures between $150^{\circ} \mathrm{C}$ and $210^{\circ} \mathrm{C}$. The model was calibrated to a measured ageing curve, but all parameters have physical relevance. The model predicts the yield strength on overageing well, while the underaged condition is less well described. The model has been implemented in a development version of MAGMAnon-ferrous.

> The Hollomon equation can be used to describe the plastic deformation when shearable precipitates are present, while the Ludwigson equation is needed when a supersaturated solid solution is present. The plastic curve of the Al-Si-Cu alloy has a complicated shape which is thought to be caused by non-coherent precipitates and the Hollomon and Ludwigson equations can not describe the shape of the curve very well. The KM model for pure metals can be used to model the plastic deformation for Al-Si$\mathrm{Mg}$ and $\mathrm{Al}-\mathrm{Si}-\mathrm{Cu}-\mathrm{Mg}$ alloys. A modified version of the $\mathrm{KM}$ model for non-coherent precipitates was used for the $\mathrm{Al}-\mathrm{Si}-\mathrm{Cu}$ alloy which gave a perfect fit to the whole plastic part of the stress-strain curve. 


\subsection{FUTURE WORK}

\section{Solidification}

$>$ The distance between $\mathrm{Mg} / \mathrm{Cu}$ rich phases is measured and used as an input to the solution treatment model. By investigating the position of the phases in the microstructure by for example grain boundary etching, the distance between the phases could in the future be modelled. The measured distance between the phases should also be compared with equiaxed solidified samples to see if there is a difference.

$>$ Back diffusion can be included in the model to predict the yield strength for the as-cast condition.

\section{Solution treatment}

$>$ The reported high diffusivity of $\mathrm{Cu}$ in the Al-Si eutectic should be verified by solution treatment of a eutectic Al-Si-Cu alloy or a binary Al-Cu alloy.

$>$ To widen the alloys the model can handle the phase diagram of $\mathrm{Al}-\mathrm{Si}-\mathrm{Cu}-\mathrm{Mg}$ alloys Quench need to be studied.

$>$ Quench and natural ageing is not included in the present model. A rapid quench and no natural ageing are assumed. Quench and natural ageing is however known to influence the shape of the ageing curve and should be included in the model.

\section{Artificial ageing}

$>$ Experiments are needed to determine which are the parameters that influence the fractions of the $\beta$ " and Q" phases formed during artificial ageing in order to be able to develop a yield strength model for Al-Si-Cu-Mg alloys.

$>$ The modelling of yield strength for the underaged condition of the Al-Si-Mg alloy needs further attention, for example to see if small clusters could be introduced in the model instead of $\mathrm{Mg}$ and $\mathrm{Si}$ atoms in solid solution.

If mathematical relations between the parameters $\left(\theta_{0}, \beta, K\right)$ in the $\mathrm{KM}$ strain hardening theory and the microstructure (solid solution concentration, fraction and radius of precipitates) can be derived for various alloy groups a model for plastic deformation of defect free alloys can be developed. The UTS and elongation to fracture can then be derived using Considère's criterion for necking. 


\section{REFERENCES}

[1] B. Thundal, Aluminium, 1 ed., Almqvist och Wiksell, Kristianstad, 1991.

[2] I.J. Polmear, Light alloys, 3 ed., Butterworth-Heinemann, Oxford, 2000.

[3] E. Hornbogen, J. Light Met. 1 (2001) 127-132.

[4] I.J. Polmear, in: J.F. Nie, A.J. Morton, B.C. Muddle (Eds.) 9th International Conference on Aluminium Alloys, Materials Forum, Brisbane, Australia, 2004.

[5] J.E. Martin, Precipitation Hardening, 2nd ed., Butterworth-Heinemann, Oxford, 1998.

[6] A. Guinier, Mater. Sci. Forum 217-222 (1996) 3-6.

[7] L. Wang, M. Makhlouf, D. Apelian, Int. J. Mater. Rev. 40 (1995) 221-238.

[8] M. Warmuzek, Aluminum-Silicon Casting Alloys, ASM International, Ohio, 2004.

[9] B. Sundman, B. Jansson, J.O. Andersson, Calphad 9 (1985) 153-190.

[10] A. Hekmat-Ardakan, X. Liu, F. Ajersch, X.G. Chen, Wear 269 (2010) 684-692. Reprinted from Wear, Wear behaviour of hypereutectic $\mathrm{Al}-\mathrm{Si}-\mathrm{Cu}-\mathrm{Mg}$ casting alloys with variable $\mathrm{Mg}$ contents, Copyright (2010), with permisson from Elsevier.

[11] D. Apelian, S. Shivkumar, G. Sigworth, AFS Trans. 137 (1989) 727-742.

[12] S.G. Shabestari, F. Shahri, J. Mater. Sci. 39 (2004) 2023-2032.

[13] G.K. Sigworth, Int. J. Metalcast. 2 (2008) 19-41.

[14] M. Tash, F.H. Samuel, F. Mucciardi, H.W. Doty, Mater. Sci. Eng. A 443 (2007) 185-201.

[15] A.L. Dons, G. Heiberg, J. Voje, J.S. Maeland, J.O. Loland, A. Prestmo, Mater. Sci. Eng. A 413-414 (2005) 561-566.

[16] E.H. Samuel, A.M. Samuel, H.W. Doty, AFS Trans. 30 (1996) 893-901.

[17] H. De La Sablonnière, F.H. Samuel, Int. J. Cast Met. Res. 9 (1996) 195-211.

[18] J.A. Taylor, D.H. St John, J. Barresi, M.J. Couper, Mater. Sci. Forum 331-337 (2000) 277282.

[19] Q.G. Wang, C.H. Caceres, J.R. Griffiths, Metall. Mater. Trans. A 34 (2003) 2901-2912.

[20] S. Seifeddine, S. Johansson, I.L. Svensson, Mater. Sci. Eng. A 490 (2008) 385-390.

[21] J. Campbell, Castings, 2nd ed., Butterworth Heinemann Oxford, 2007.

[22] R.N. Lumley, D.R. Gunasegaram, M. Gershenzon, R.G. O'Donnell, Proceedings of the 111th Metalcasting Congress, Houston, Texas, 2007.

[23] S. Shivkumar, S. Ricci Jr, C. Keller, D. Apelian, J. Heat Treating 8 (1990) 63-70.

[24] F.H. Samuel, J. Mater. Sci. 33 (1998) 2283-2297. 
[25] J.H. Sokolowski, X.C. Sun, G. Byczynski, D.O. Northwood, D.E. Penrod, R. Thomas, A. Esseltine, J. Mater. Process. Tech. 53 (1995) 385-392.

[26] Y.M. Han, A.M. Samuel, F.H. Samuel, H.W. Doty, Int. J. Cast Met. Res. 21 (2008) 387-393.

[27] L. Lasa, J.M. Rodriguez-Ibabe, J. Mater. Sci. 39 (2004) 1343-1355.

[28] A.L. Dons, L. Pedersen, S. Brusethaug, Aluminium 76 (2000) 294-297.

[29] M. Tiryakioglu, R.T. Shuey, Metall. Mater. Trans. B 38 (2007) 575-582.

[30] S. Seifeddine, G. Timelli, I.L. Svensson, Int. Foundry Res. 59 (2007) 2-10.

[31] D.L. Zhang, L. Zheng, Metall. Mater. Trans. A 27 (1996) 3983-3991.

[32] P.A. Rometsch, G.B. Schaffer, Int. J. Cast Metal. Res. 12 (2000) 431-439.

[33] G.A. Edwards, K. Stiller, G.L. Dunlop, M.J. Couper, Acta Mater. 46 (1998) 3893-3904.

[34] N. Maruyama, R. Uemori, N. Hashimoto, M. Saga, M. Kikuchi, Scr. Mater. 36 (1997) 89-93.

[35] Y.J. Li, S. Brusethaug, A. Olsen, Scr. Mater. 54 (2006) 99-103.

[36] G. Wang, Q. Sun, L. Feng, L. Hui, C. Jing, Mater. Des. 28 (2007) 1001-1005.

[37] X. Wang, S. Esmaeili, D.J. Lloyd, Metall. Mater. Trans. A 37 (2006) 2691-2699.

[38] D.G. Eskin, J. Mater. Sci. 38 (2003) 279-290.

[39] X. Wang, W.J. Poole, S. Esmaeili, D.J. Lloyd, J.D. Embury, Metall. Mater. Trans. A 34 (2003) 2913-2924.

[40] H.G. Kang, M. Kida, H. Miyahara, K. Ogi, AFS Trans. 27 (1999) 507-515.

[41] H.R. Shercliff, M.F. Ashby, Acta Metall. Mater. 38 (1990) 1789-1802.

[42] S. Esmaeili, D.J. Lloyd, W.J. Poole, Acta Mater. 51 (2003) 2243-2257.

[43] O.R. Myhr, O. Grong, S.J. Andersen, Acta Mater. 49 (2001) 65-75.

[44] J.D. Robson, Acta Mater. 52 (2004) 4669-4676.

[45] G. Liu, J. Sun, C.W. Nan, K.H. Chen, Acta Mater. 53 (2005) 3459-3468.

[46] D.M. Stefanescu, Science and Engineering of Casting Solidification, Kluwer Academic / Plenum Publisher, New York, 2002.

[47] P.A. Rometsch, L. Arnberg, D.L. Zhang, Int. J. Cast Metal. Res. 12 (1999) 1-8.

[48] A.L. Dons, J. Light Met. 1 (2001) 133-149.

[49] P. Shewmon, Diffusion in Solids, Minerals, Metals \& Materials Society, Warrendale, 1989.

[50] R. Kampmann, H. Eckerlebe, R. Wagner, Mater. Res. Soc. Symp. Proc. 57 (1987) 525-542.

[51] A. Deschamps, Y. Brechet, Acta Mater. 47 (1998) 293-305.

[52] S. Esmaeili, D.J. Lloyd, W.J. Poole, Acta Mater. 51 (2003) 3467-3481.

[53] A.J. Ardell, Metall. Trans. A 16 (1985) 2131-2165.

[54] V. Gerold, in: F.R.N. Nabarro (Ed.) Dislocations in solids, North-Holland, 1979, pp. 222.

[55] J.H. Hollomon, Trans. AIME 162 (1945) 268-290.

[56] D.C. Ludwigson, Metall. Trans. 2 (1971) 2825-2828.

[57] Y. Estrin, H. Mecking, Acta Metall. 32 (1984) 57-70.

[58] U.F. Kocks, H. Mecking, Prog. Mater. Sci. 48 (2003) 171-273. 
[59] H. Mecking, Proceeding of TMS-AIME, Cincinnati, Ohio, 1975.

[60] S.G. Shabestari, H. Moemeni, J. Mater. Process. Technol. 153-154 (2004) 193-198.

[61] L. Pedersen, L. Arnberg, Mater. Sci. Eng. A 241 (1998) 285-289.

[62] A.L. Dons, L. Pedersen, L. Arnberg, Mater. Sci. Eng. A 271 (1999) 91-94.

[63] Y.M. Han, A.M. Samuel, F.H. Samuel, S. Valtierra, H.W. Doty, AFS Trans. 116 (2008) 7990.

[64] M. Qian, F. Yi, D. Zhang, X. Pan, H.D. Brody, J.E. Morral, in: Proceedings from Materials Solutions Conference 2003, ASM International, Pittsburgh, PA., United States, 2003, pp. 69-78.

[65] P.A. Rometsch, G.B. Schaffer, J.A. Taylor, Int. J. Cast Metal. Res. 14 (2001) 59-69.

[66] D.L. Zhang, L.H. Zheng, D.H. StJohn, J. Light Met. 2 (2002) 27-36.

[67] Z. Li, A.M. Samuel, F.H. Samuel, C. Ravindran, S. Valtierra, J. Mater. Sci. 38 (2003) 1203 1218.

[68] G. Wang, X. Bian, W. Wang, J. Zhang, Mater. Lett. 57 (2003) 4083-4087.

[69] Y. Ma, J. Fang, F. Yi, K. Song, H.D. Brody, J.E. Morral, in: Materials Science and Technology Conference and Exhibition 2009, ASM International, Pittsburgh, 2009, pp. 24102421.

[70] E. Cerri, E. Evangelista, S. Spigarelli, P. Cavaliere, F. DeRiccardis, Mater. Sci. Eng. A 284 (2000) 254-260.

[71] C.H. Cáceres, Int. J. Cast Met. Res. 10 (1998) 293-299.

[72] M. Tiryakioglu, J. Campbell, J.T. Staley, Mater. Sci. Eng. A 368 (2004) 205-211.

[73] M. Kaczorowski, M.W. Grabski, J. Sawicki, P. Murza-Mucha, J. Mater. Sci. 14 (1979) 27812786.

[74] D.L. Zhang, D.H. StJohn, Casting \& Solidification of Light Alloys, Gold Coast, 1995, pp. 2125.

[75] R.W. Hertzberg, Deformation and fracture mechanics of engineering materials, 4 ed., John Wiley \& Sons, Inc., Hoboken, NJ, 1996.

[76] N.D. Alexopoulos, M. Tiryakioglu, Mater. Sci. Eng. A 507 (2009) 236-240.

[77] C.H. Cáceres, I.L. Svensson, J.A. Taylor, Int. J. Cast Met. Res. 15 (2003) 531-543.

[78] L.M. Cheng, W.J. Poole, J.D. Embury, D.J. Lloyd, Met. Mater. Trans. A 34 A (2003) 24732481 .

[79] W.J. Poole, X. Wang, D.J. Lloyd, J.D. Embury, Philos. Mag. 85 (2005) 3113-3135.

[80] A. Simar, Y. Bréchet, B. de Meester, A. Denquin, T. Pardoen, Acta Mater. 55 (2007) 61336143.

[81] Y. Estrin, in: A.S. Krausz, K. Krausz (Eds.) Unified constitutive laws of plastic deformation, Academic Press, Inc., San Diego, 1996, pp. 69-106.

[82] M. Tiryakioglu, J.T. Staley Jr, J. Campbell, Mater. Sci. Eng. A 487 (2008) 383-387.

[83] D. Zhang, J. Peng, T. Liu, Mater. Sci. Eng. A 425 (2006) 78-82.

[84] S.J. Andersen, H.W. Zandbergen, J. Jansen, C. TrAeholt, U. Tundal, O. Reiso, Acta Mater. 46 (1998) 3283-3298.

[85] C.D. Marioara, S.J. Andersen, J. Jansen, H.W. Zandbergen, Acta Mater. 49 (2001) 321-328.

[86] C.D. Marioara, H. Nordmark, S.J. Andersen, R. Holmestad, J. Mater. Sci. 41 (2006) 471-478. 
REFERENCES

[87] B. Rinderer, M. Couper, X. Xiong, S. Gao, J.F. Nie, Mater. Sci. Forum 654-656 (2010) 590595.

[88] P.B. Hirsch, F.J. Humphreys, in: A.S. Argon (Ed.) Physics of strength and plasticity, MIT Press, Cambridge, 1969, pp. 189-216.

[89] P.A. Rometsch, G.B. Schaffer, Mater. Sci. Eng. A 325 (2002) 424-434. 


\section{APPENDED PAPERS}

$\begin{array}{ll}\text { Supplement I - } & \text { E. Sjölander, S. Seifeddine: The heat treatment of } A l-S i-C u-M g \\ \text { casting alloys. Journal of Materials Processing Technology } 210(2010) \\ \text { 1249-1259. }\end{array}$

Supplement II - $\quad$ E. Sjölander, S. Seifeddine: Optimisation of solution treatment of cast Al-Si-Cu alloys. Materials and Design 31 (2010) S44-S49.

Supplement III - $\quad$ E. Sjölander, S. Seifeddine: Optimisation of solution treatment of cast Al-7Si-0.3Mg and Al-8Si-3Cu-0.5Mg alloys. Submitted to Metallurgical and Materials Transactions A.

Supplement IV E. Sjölander, S. Seifeddine: Artificial ageing of Al-Si-Cu-Mg casting alloys. Submitted to Materials Science and Engineering A.

Supplement V - $\quad$ E. Sjölander, S. Seifeddine: Influence of alloy composition, solidification rate and artificial ageing on the plastic deformation of $\mathrm{Al}-\mathrm{Si}-\mathrm{Cu}-\mathrm{Mg}$ casting alloys. Submitted to Materials Science and Engineering A.

Supplement VI - $\quad$ E. Sjölander, S. Seifeddine, I. L. Svensson: Modelling the yield strength of heat treated Al-Si-Mg casting alloys. Submitted to International Journal of Cast Metals Research 
